\title{
Targeting of $\mathrm{N}-\mathrm{CoR}$ and histone deacetylase 3 by the oncoprotein $v$-ErbA yields a chromatin infrastructure-dependent transcriptional repression pathway
}

\author{
Fyodor D.Urnov ${ }^{1,2}$, Janet Yee ${ }^{2,3}$, \\ Laurent Sachs ${ }^{2,4}$, Trevor N.Collingwood ${ }^{1,2}$, \\ Anton Bauer ${ }^{5}$, Hartmut Beug ${ }^{5}$, Yun-Bo Shi ${ }^{2}$ \\ and Alan P.Wolffe ${ }^{1,6}$ \\ ${ }^{1}$ Sangamo Biosciences, Point Richmond Technology Centre, 501 Canal \\ Boulevard, Suite A100, Richmond, CA $94804,{ }^{2}$ Laboratory of \\ Molecular Embryology, National Institute of Child Health and Human \\ Development, National Institutes of Health, Building 18T, Room 106 , \\ Bethesda, MD 20892, USA and ${ }^{5}$ Institute of Molecular Pathology, Dr. \\ Bohr-Gasse 7, Vienna A-1030, Austria \\ ${ }^{3}$ Present address: Department of Biology, Trent University, \\ Peterborough, Ontario, Canada \\ ${ }^{4}$ Present address: Laboratoire de Physiologie, MNHN, UMR CNRS, \\ Paris, France \\ ${ }^{6}$ Corresponding author \\ e-mail: awolffe@sangamo.com
}

Transcriptional repression by nuclear hormone receptors is thought to result from a unison of targeting chromatin modification and disabling the basal transcriptional machinery. We used Xenopus oocytes to compare silencing effected by the thyroid hormone receptor (TR) and its mutated version, the oncoprotein v-ErbA, on partly and fully chromatinized TR-responsive templates in vivo. Repression by v-ErbA was not as efficient as that mediated by TR, was significantly more sensitive to histone deacetylase (HDAC) inhibitor treatment and, unlike TR, v-ErbA required mature chromatin to effect repression. We find that both v-ErbA and TR can recruit the corepressor $\mathrm{N}-\mathrm{CoR}$, but, in contrast to existing models, show a concomitant enrichment for HDAC3 that occurs without an association with Sin3, HDAC1/ RPD3, Mi-2 or HDAC5. We propose a requirement for chromatin infrastructure in N-CoR/HDAC3effected repression and suggest that the inability of v-ErbA to silence on partly chromatinized templates may stem from its impaired capacity to interfere with basal transcriptional machinery function. In support of this notion, we find v-ErbA to be less competent than TR for binding to TFIIB in vitro and in vivo. Keywords: histone deacetylase (HDAC)3/N-CoR/thyroid hormone receptor/transcriptional repression/v-ErbA

\section{Introduction}

Embryogenesis and adult ontogeny in metazoa offer many examples of particular cell types undergoing a regulated transition from proliferation to cell cycle arrest and differentiation. A complex phenomenon, in specific instances this event can be experimentally triggered by a simple signal, e.g. hormonal treatment. Nuclear hormone receptors (NHRs), including those for vitamin D (Haussler et al., 1997), thyroid hormone ( $\mathrm{T}_{3}$ ) (Brown et al., 1995; Tata, 1996) and 9-cis retinoic acid (Sucov and Evans, 1995), provide excellent models for this transition. According to current data, genes required for cell cycle arrest and the differentiated phenotype are silenced by DNA-bound receptors in the absence of hormone and are activated in its presence (Xu et al., 1999). An important and poorly understood aspect of repression by NHRs stems from the necessity for their constitutive function on chromatin templates (Samuels et al., 1982). In proliferating cells, cycles of DNA replication, chromatin assembly and chromosome condensation impose on the unliganded receptor the requirement for continued association with DNA to mediate repression on a variety of chromatin substrates, including those that are in the process of assembly (Adams and Kamakaka, 1999).

Studies of thyroid hormone receptor (TR) have found two pathways likely to be involved in transcriptional repression (Hanna-Rose and Hansen, 1996). In vitro experiments with purified DNA templates (Fondell et al., 1993, 1996; Tong et al., 1995) indicated that unliganded TR binds various components of the basal transcriptional machinery, including TATA-binding protein (TBP) and transcription factor IIB (TFIIB), and suggested that the receptor interferes with an early step of pre-initiation complex formation, possibly by affecting the association between TFIIB and DNA-bound TBP (TFIID).

In separate studies, use of unliganded TR as 'bait' in yeast two-hybrid screens (Chen and Evans, 1995; Hoerlein et al., 1995; Seol et al., 1995; Dressel et al., 1999) led to the identification of several large polypeptides, termed 'corepressors'. In assays based on transient transfection of plasmids carrying synthetic multimerized TR response elements (TREs), corepressors potentiate repression by TR and other members of the nuclear hormone superfamily, and a positive correlation exists between the ability of mutated forms of TR to interact physically with corepressors (as gauged from in vitro assays) and their ability to silence transcription driven by such artificial promoters (Torchia et al., 1998; Xu et al., 1999). Functional aspects of corepressor action were revealed when biochemical approaches identified their physical association with the histone deacetylase (HDAC) RPD3/HDAC1 via the adapter-auxiliary corepressor molecule Sin3 (Heinzel et al., 1997; Nagy et al., 1997). Together with data that HDAC inhibitors such as trichostatin A (TSA) alleviate receptor-mediated silencing, this added TR and other class II NHRs to a growing list of transcriptional repressors in metazoa that exploit HDAC targeting to effect repression, such as Mad/Max (Heinzel et al., 1997; Laherty et al., 1997), Rb (Brehm et al., 1998; Luo et al., 1998; Magnaghi-Jaulin et al., 1998), groucho (Chen et al., 1999), MeCP2 (Jones et al., 1998; Nan et al., 1998) and Ikaros (Koipally et al., 1999). 
The relative contribution to receptor-effected silencing made by recruiting corepressors versus that made by direct interaction of the unliganded receptor with the basal transcriptional machinery remains to be determined. It is also unclear whether HDAC function accounts for the entirety of repression mediated by corepressors recruited by unliganded NHRs to their natural targets in a native chromosomal context. Published data (Muscat et al., 1998; Wong and Privalsky, 1998) are consistent with the notion that such corepressors as mSin3a, SMRT and N-CoR exploit both HDAC-dependent and -independent mechanisms for effecting repression; the latter may also involve interactions with the basal transcriptional machinery. In the present study we addressed this problem via the use of two well-studied regulatory factors, the NHR TR/retinoid $\mathrm{X}$ receptor $(\mathrm{RXR})$ and the oncoprotein $\mathrm{v}$-ErbA.

The avian erythroblastosis virus (AEV) causes fatal erythroleukemia in chickens (Beug et al., 1994); leukemic transformation requires the action of normal or mutated oncogenic receptor tyrosine kinases in cooperation with a mutated version of chicken TR $\alpha$, the oncoprotein $\mathrm{v}$-ErbA (Sap et al., 1986; Weinberger et al., 1986). v-ErbA is thought to constitutively silence currently unidentified TRregulated genes required for proliferation induction, differentiation arrest and/or protection from apoptosis in hematopoietic precursor cells (Damm et al., 1989; Sap et al., 1989; Beug et al., 1996; Bauer et al., 1998; Stunnenberg et al., 1999). This property of v-ErbA is known to derive from nine point mutations in its ligandbinding domain that decrease affinity for thyroid hormone (Munoz et al., 1988; Zenke et al., 1990), as well as the deletion of a conserved C-terminal $\alpha$-helix that mediates transcriptional activation by various NHRs (Danielian et al., 1992; Saatcioglu et al., 1993; Tone et al., 1994; Moras and Gronemeyer, 1998). Importantly, $\mathrm{T}_{3}$ treatment not only induces cell cycle arrest and differentiation of primary chicken erythroblasts, but also markedly decreases the amount of HDAC activity associated with TR (Bauer et al., 1998). These data provide strong evidence supporting a functional role for HDAC recruitment in silencing by TR.

The interest in and utility of v-ErbA for investigating mechanisms of repression by TR stems from the presumed nature of this oncoprotein as a 'pure' transcriptional silencer in conjunction with its function as an oncogene: while TR is competent to engage in functional interactions pertaining to both repression and activation (Baniahmad et al., 1993; Tone et al., 1994; Tong et al., 1995; Lavigne et al., 1999), functional and biochemical data for v-ErbA can, potentially, point to the relevance of such interactions to repression per se. Importantly, in contrast to $\mathrm{v}$-ErbA, TR does not contribute to oncogenesis unless strongly overexpressed and stabilized in a repressive conformation via the withdrawal of TR and RXR ligands (Bauer et al., 1998). Studies as to the mechanism by which v-ErbA represses target genes and causes leukemia have been severely limited by the fact that repression by v-ErbA has not been analyzed in a native chromatin environment. The Xenopus oocyte system is uniquely suited to addressing this issue, since microinjection of purified double-stranded DNA into the oocyte nucleus leads to progressive chromatinization of the injected DNA (Almouzni and Wolffe, 1993b). By generating functional and biochemical data for v-ErbA-mediated gene silencing in such a context, new insights into the relevance of $\mathrm{v}$-ErbA interactions with corepressors versus basal transcription factors to the mechanisms of repression per se can be expected.

We report here our comparative analysis of chicken $\mathrm{TR} \alpha(\mathrm{c}-\mathrm{ErbA})$ and $\mathrm{v}$-ErbA as transcriptional regulators of the Xenopus TR $\beta$ A gene promoter. We find that both proteins can repress basal transcription in this system, but repression by v-ErbA is more dependent on template chromatinization than that effected by TR, and is also significantly more sensitive to treatment with the HDAC inhibitor, TSA. We find, however, that $\mathrm{v}$-ErbA is quite efficient in recruiting the corepressor N-CoR and HDAC activity. Suprisingly, no $\operatorname{Sin} 3$ or $\mathrm{HDAC} 1$, but rather HDAC3, was found enriched in the v-ErbA-N-CoR complex. Similarly, we show that ligand-regulated targeting of N-CoR to TR is accompanied by an enrichment for HDAC3, but not Sin3, HDAC1 or the Mi-2 ATPase. Finally, we show that both unliganded TR and v-ErbA can bind TBP in vitro, but that v-ErbA is less competent than TR for binding to TFIIB in vitro and in vivo. We propose that targeting of the N-CoR-HDAC3 complex represents the chromatin-dependent component of transcriptional repression effected by $\mathrm{v}$-ErbA and by TR.

\section{Results \\ v-ErbA and unliganded chicken TR silence basal transcription driven by the Xenopus TR $\beta A$ gene promoter}

We used mRNA microinjection to establish that chicken TR $\alpha$ and v-ErbA can be synthesized in the Xenopus oocyte (Figure 1A, lanes 3 and 4), and then used gel-shift analysis and genomic DNase I footprinting to show that the resulting proteins are competent for binding to the previously characterized (Shi et al., 1992; Machuca et al., 1995; Wong et al., 1995, 1997) $\mathrm{T}_{3^{-}}$and TR-responsive upstream enhancer of the Xenopus TR $\beta$ A gene (data not shown). An in vivo transcription assay (Figure 1B) demonstrated that both unliganded Xenopus TR $\beta$ and chicken TR $\alpha$ efficiently silenced basal transcription of the TR $\beta A$ gene (Figure 1B, compare lanes 3 and 4 with 5 and 7), and treatment with $\mathrm{T}_{3}$ led to relief of transcriptional repression (lanes 6 and 8). As expected (Zenke et al., 1990), v-ErbA silenced basal transcription of the TR $\beta A$ gene in a ligandinsensitive manner (Figure 1B, lanes 9 and 10), albeit not as efficiently as TR (compare lanes 5 and 7 with 9 and 10). We conclude that v-ErbA can moderately repress basal transcription of a Xenopus TR-regulated gene in vivo.

\section{HDAC is required for establishing and maintaining transcriptional repression effected by v-ErbA and chicken TR}

Targeted modification of chromatin provides a candidate mechanism for transcriptional silencing by NHRs (Wolffe, 1997; Torchia et al., 1998; Xu et al., 1999); work from this and other laboratories pointed to a role for HDAC in mediating repression (Heinzel et al., 1997; Nagy et al., 1997; Wong et al., 1998b). We evaluated the capacity of an HDAC inhibitor, TSA, to interfere with transcriptional repression effected by $\mathrm{v}$-ErbA and by unliganded chicken TR. 


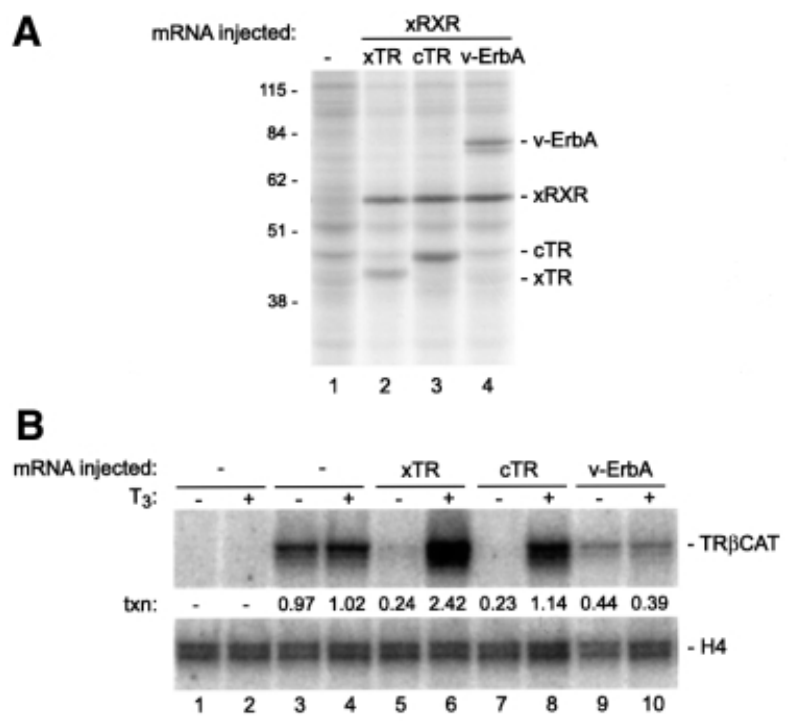

Fig. 1. Chicken TR $\alpha$ (c-ErbA) and v-ErbA can be expressed in the Xenopus oocyte and can repress transcription driven by the TR $\beta A$ gene promoter. (A) In vivo synthesis of chicken TR $\alpha$ and v-ErbA. Oocytes were left uninjected (lane 1), or injected with $5 \mathrm{ng}$ of Xenopus $\mathrm{RXR} \alpha$ mRNA along with $5 \mathrm{ng}$ of mRNA for Xenopus TR $\beta$ (lane 2), chicken TR $\alpha$ (lane 3) or v-ErbA (lane 4) mRNA. The oocytes were cultured in the presence of $\left[{ }^{35} \mathrm{~S}\right]$ methionine for $10 \mathrm{~h}$, and oocyte protein extract was prepared as described in Materials and methods. Proteins synthesized in the oocyte during the incubation period were visualized by SDS-PAGE and autoradiography. The positions of the proteins derived from the injected mRNAs are indicated to the right of the autoradiograph; molecular weight marker size is indicated to the left. (B) Transcriptional regulation by chicken TR $\alpha$ and v-ErbA. Groups of 20 oocytes were injected into the cytoplasm with $5 \mathrm{ng}$ of Xenopus RXR $\alpha$ mRNA (lanes 5-10) along with 5 ng of Xenopus TR $\beta$ (lanes 5 and 6), chicken $\operatorname{TR} \alpha$ (lanes 7 and 8) or v-ErbA (lanes 9 and 10) mRNA; the oocytes in lanes 1-4 were not injected with mRNA. After a $12 \mathrm{~h}$ incubation, the oocytes were left uninjected (lanes 1 and 2), or injected into the nucleus with $1 \mathrm{ng}$ (lanes 3-10) of double-stranded reporter plasmid DNA (pTR $\beta A$ ); the oocytes were then cultured for an additional $16 \mathrm{~h}$ in the absence $(-)$ or presence $(+)$ of $100 \mathrm{nM}$ thyroid hormone $\left(\mathrm{T}_{3}\right)$, following which total RNA was extracted and levels of $\mathrm{H} 4$ and TR $\beta A$ mRNA were measured by primer extension as described in Materials and methods. The primer against histone $\mathrm{H} 4 \mathrm{mRNA}$ that is stored in the oocyte was included in all reactions to serve as a loading control. Transcriptional activity (txn) was quantitated by normalizing the signal for TR $\beta$ A in each sample against that for $\mathrm{H} 4$ in that sample, and expressing the result in arbitrary units where 1 unit = transcriptional activity in the absence of injected mRNA (the average of signals from lanes 3 and 4).

Since histone deacetylation is required for chromatin assembly (Adams and Kamakaka, 1999), we used two distinct experimental regimens to distinguish between relief of transcriptional repression via inhibition of HDAC activity targeted by receptor and a failure to establish a repressed state due to the inability to assemble chromatin properly; as shown in Figure 2A, following mRNA injection and receptor synthesis, we either included TSA in the medium immediately after DNA injection (lower half), or allowed chromatin assembly in the absence of TSA, and then monitored its effects on more completely assembled chromatin templates (upper half).

Chromatin was assembled in the absence (Figure 2B, lane 2) or presence of receptor (TR, lane 6; v-ErbA, lane 15) for $16 \mathrm{~h}$. As expected (Figure 1B), both proteins repressed basal transcription, albeit with different efficiencies. The oocytes were then placed into TSA or $\mathrm{T}_{3}$, and the effect of this treatment on transcriptional activity of the TR $\beta A$ promoter was monitored over the course of the next 6 h. As shown in Figure 2B, lanes 12-14, TSA relieved transcriptional repression established by chicken TR; we noted that from a kinetic standpoint, at early timepoints the addition of ligand (lanes 8-10) had the same effect on transcription from a TR-bound promoter as treatment with the HDAC inhibitor (lanes 12-14), while over the course of $16 \mathrm{~h}, \mathrm{~T}_{3}$ stimulated transcription to a greater extent than TSA did (compare lanes 7 and 11). TSA efficiently relieved repression established by v-ErbA (Figure 2B, lanes 17-19) and had a reproducibly more significant effect on v-ErbA-repressed chromatin than on TR-repressed chromatin (compare lane 14 with lane 19).

It is informative to compare the effect that TSA has on basal transcription (Figure 2B, lanes 4 and 5) with its effect on receptor-repressed chromatin. When the promoter is bound by TR, TSA treatment reproducibly relieves transcriptional repression to only a fraction of the level seen in the absence of TR (compare lane 5 with lane 14). In contrast, the stimulation of transcription by TSA on a v-ErbA-repressed template reproducibly approached that exerted by TSA in the absence of v-ErbA (Figure 2B, compare lane 5 with lane 19).

These experiments establish that an HDAC inhibitor will prevent both the establishment as well as the maintenance of transcriptional silencing effected by chicken TR or by v-ErbA, and that a chromatin template silenced by v-ErbA is significantly more sensitive to TSA treatment than a template silenced by TR.

\section{Distinct requirements for template chromatinization in repression by v-ErbA and by $T R$ in vivo}

The robust relief of v-ErbA-effected repression by an HDAC inhibitor (Figure 2B) suggested to us that the properties of v-ErbA as a transcriptional regulator of the TR $\beta A$ gene might be affected by the extent to which the DNA target is assembled into chromatin. The Xenopus oocyte system is uniquely suited to addressing this issue experimentally: microinjection of purified doublestranded DNA into the oocyte nucleus leads to gradual chromatinization of the injected DNA over the course of 3-12 h (Almouzni et al., 1990; Almouzni and Wolffe, 1993b); thus, one can examine the transcriptional activity of DNA constructs at various levels of assembly into chromatin.

Figure $3 \mathrm{~A}$ and $\mathrm{B}$ shows that at early timepoints following injection of DNA into the oocyte nucleus (Figure 3A, lanes 3 and 4, and B, lanes 2, 3, 5 and 6), nucleosome density over the injected DNA is low and the DNA is highly accessible to micrococcal nuclease. At later timepoints, a more robust nucleosomal ladder is visualized over the injected DNA (Figure 3B, lanes 8, 9, 11 and 12), and topological criteria also indicate that chromatin is more mature (Figure 3A, lanes 5 and 6).

Figure $3 \mathrm{C}$ shows a representative result of one of several experiments in which we injected oocytes with mRNA for TR/RXR or v-ErbA/RXR and, following receptor synthesis, injected double-stranded TR $\beta$ A reporter DNA into the nucleus of control and receptor-containing oocytes. The transcriptional activity of the TR $\beta$ A promoter was then monitored over the course of time by isolating total RNA 


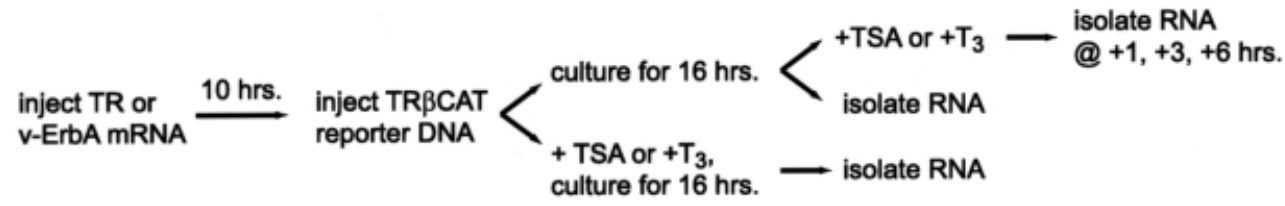

B

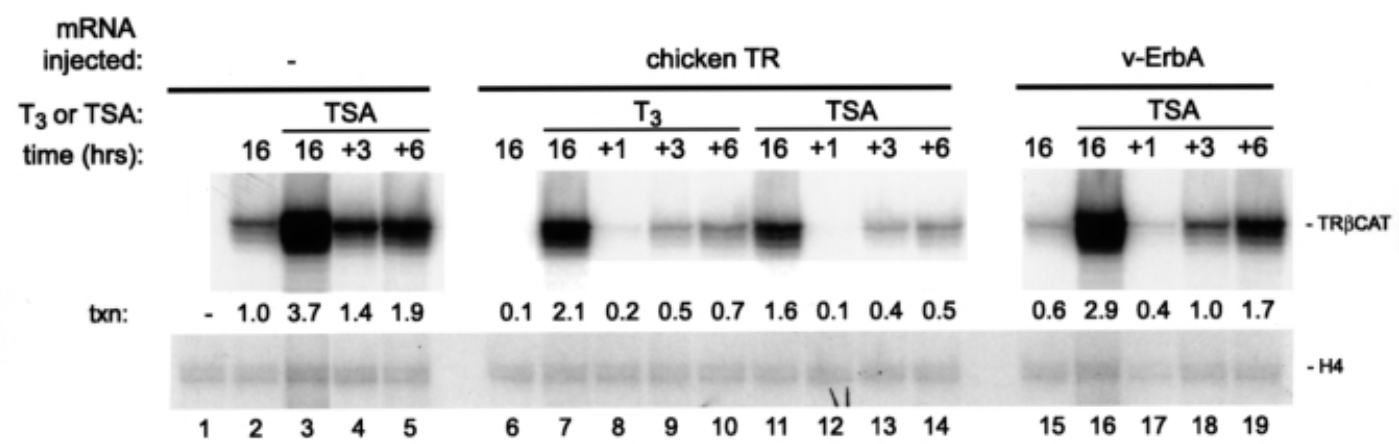

C

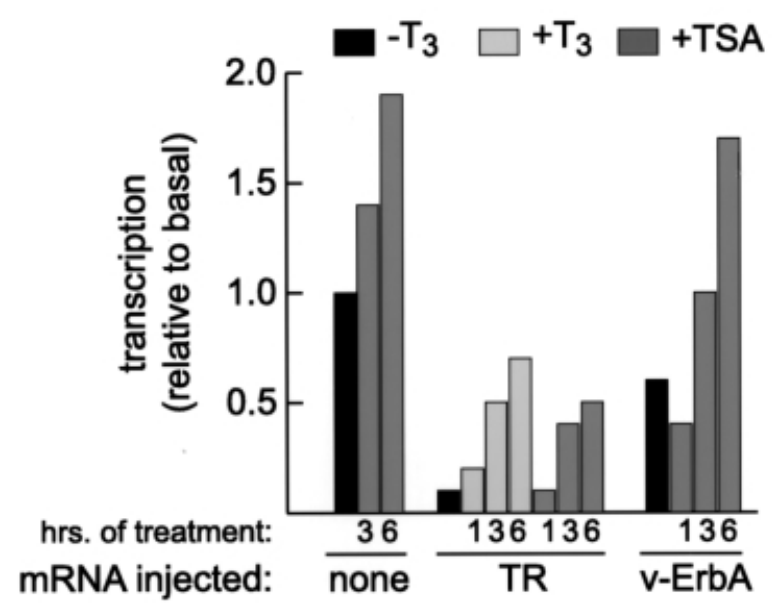

Fig. 2. Analysis of the effects of an HDAC inhibitor (TSA) on the establishment and maintenance of transcriptional silencing by TR and v-ErbA. (A) Schematic representation of the two experimental regimens used. (B) Groups of 20 oocytes were left uninjected (lanes 1-5), injected into the cytoplasm with $1 \mathrm{ng}$ each of Xenopus RXR $\alpha$ and chicken TR $\alpha$ mRNA (lanes 6-14), or $3 \mathrm{ng}$ each of Xenopus RXR $\alpha$ and wild-type v-ErbA mRNA (lanes 15-19). Following incubation for $10 \mathrm{~h}, 500 \mathrm{pg}$ of pTR $\beta$ A double-stranded reporter plasmid DNA were injected into the nucleus (all lanes except lane 1). Following injection, oocytes in lanes 2, 6 and 15 were cultured for $16 \mathrm{~h}$ and total RNA extracted for analysis (these served to measure basal transcription and the repressed state in the presence of TR or v-ErbA, respectively). Oocytes in lanes 3, 11 and 16 were cultured for the same length of time in the presence of $33 \mathrm{nM}$ TSA prior to total RNA extraction; this regimen revealed the effects on transcriptional activity of an HDAC inhibitor present during chromatin assembly and maturation (the effect of $100 \mathrm{nM} \mathrm{T}_{3}$ is shown in lane 7). To determine the effect of TSA or $\mathrm{T}_{3}$ on transcriptional activity of a mature chromatin template, groups of oocytes were injected with receptor mRNA, cultured for $10 \mathrm{~h}$ to allow protein synthesis, injected with reporter plasmid DNA, and cultured for $16 \mathrm{~h}$ to allow full chromatin assembly. TSA or T 3 ( 33 or $100 \mathrm{nM}$, respectively) was then added where indicated, and samples of 20 oocytes were removed for total RNA isolation at 1,3 and $6 \mathrm{~h}$ following addition. Transcriptional activity of the reporter plasmid was analyzed and quantitated as described in the legend to Figure 1B. (C) A graphical representation of the data in (B).

from oocytes at defined timepoints following injection. Figure 3C, lanes 3, 6 and 9, shows that the efficiency of chicken TR as a transcriptional repressor is independent of duration of time allowed for template chromatinization; over multiple experiments, we found that unliganded chicken TR $\alpha$ repressed transcription as soon as basal transcription can be detected in its absence (data not shown) - this agrees with published observations from our laboratory on Xenopus TR (Wong et al., 1997). In contrast, we found that the level of repression effected by v-ErbA was positively correlated with the length of time allowed for assembly of the injected DNA into chromatin: at an early timepoint, v-ErbA reproducibly failed to repress basal transcription (compare lanes 2 and 4 in Figure 3C). At $6 \mathrm{~h}$ post-injection, as more histone octamers became associated with the DNA (Figure 3A, lane 5 and B, lanes 8 and 9), v-ErbA exerted a moderate silencing effect on basal transcription (Figure 3C, lanes 5 and 7). Finally, when chromatin assembled on the template became more mature (Figure 3A, lane 6 and B, lanes 11 and 12), 

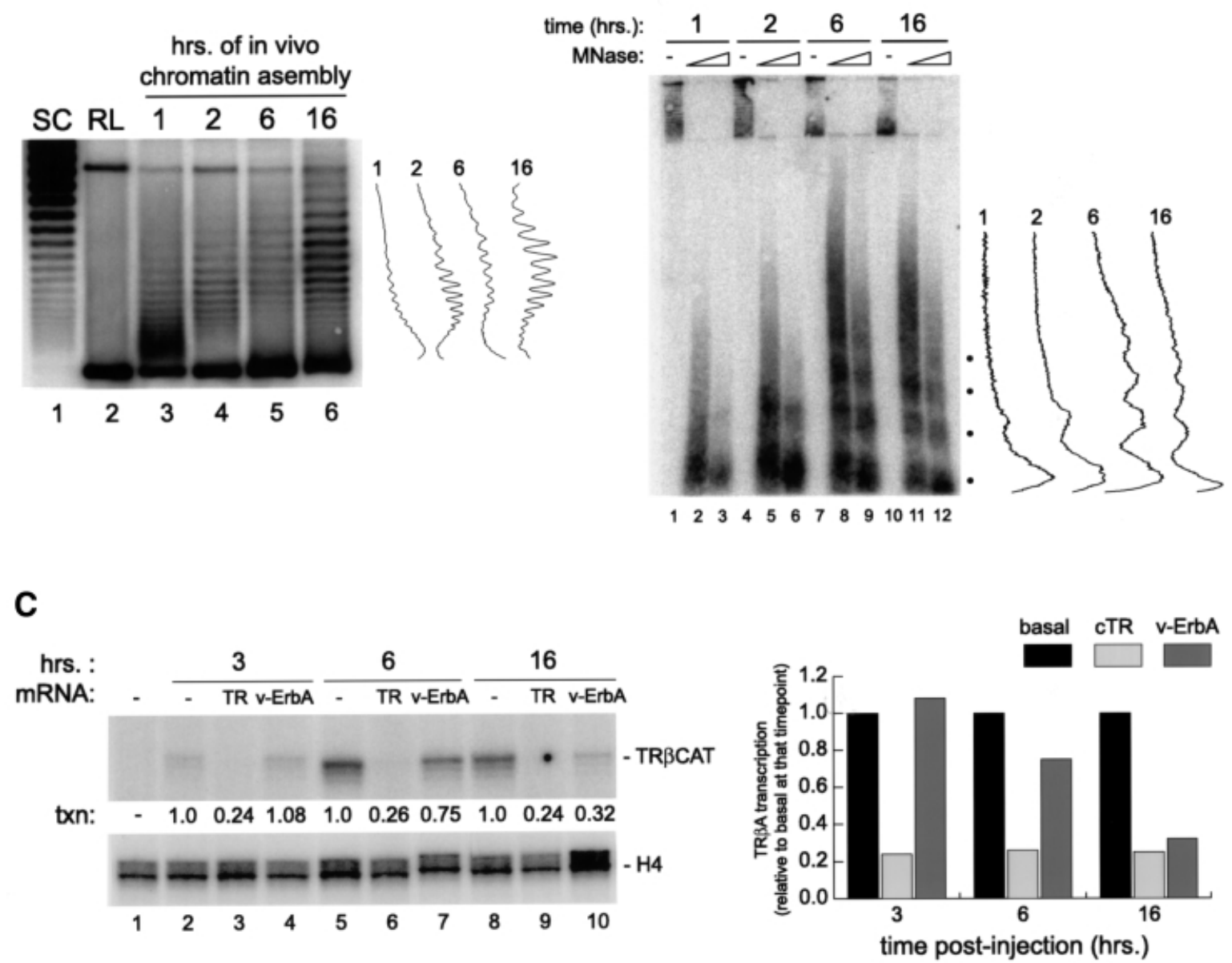

Fig. 3. An analysis of requirements for template chromatinization in transcriptional repression by TR and v-ErbA. (A) Alterations in plasmid topology due to progressive chromatinization were revealed by extracting plasmid DNA from injected oocytes (see below) at the indicated timepoints and analyzing the samples on a chloroquine-containing gel along with a sample of supercoiled (lane 1) and relaxed (lane 2) plasmid. Southern blotting was performed with a $0.8 \mathrm{~kb} E c o \mathrm{RI}-$ SmaI fragment corresponding to positions -1325 to -515 in the TR $\beta \mathrm{A}$ gene promoter. PhosphorImager-generated scans of data from the indicated timepoints are shown to the right of the gel. (B) A large group of oocytes was injected into the nucleus with 3 ng of pTR $\beta$ A double-stranded reporter plasmid DNA. At indicated timepoints, 30 oocytes were removed, homogenized as described in Materials and methods, and 1/3 of the sample was left untreated with nuclease (lanes 1, 4, 7 and 10), or treated with 30 or 120 Worthington units of MNase (the first and second lane of each pair, respectively). DNA was extracted, fractionated on a $2 \%$ agarose gel and analyzed by Southern blotting as described in Materials and methods. PhosphorImager-generated scans of data from the right lane of each pair at the indicated timepoints are shown to the right of the gel. (C) A large group of oocytes was uninjected (lanes 1,2, 5 and 8), injected into the cytoplasm with $1 \mathrm{ng}$ each of Xenopus RXR $\alpha$ and chicken TR $\alpha$ mRNA (lanes 3, 6 and 9), or 2 ng each of Xenopus RXR $\alpha$ and wild-type v-ErbA mRNA (lanes 4, 7 and 10). Following incubation for $10 \mathrm{~h}$, $500 \mathrm{pg}$ of pTR $\beta$ A double-stranded reporter plasmid DNA were injected into the nucleus (all lanes except lane 1). At 3, 6 and $16 \mathrm{~h}$ following DNA injection (lanes $2-4,5-7$ and 8-10, respectively), samples of 20 oocytes were removed and total RNA isolated. Transcriptional activity of the reporter was analyzed by primer extension as described in the legend to Figure 1B. For each timepoint the basal level of transcription (lanes 2, 5 and 8 , respectively) was set to 1.0. A graphical representation of the data is shown to the right of the autoradiograph.

repression by $\mathrm{v}$-ErbA reproducibly reached its maximal levels (Figure 3C, lanes 8 and 10).

The experiments described in this section resulted from our observation that chromatin templates repressed by TR and $\mathrm{v}$-ErbA are differentially sensitive to an HDAC inhibitor (Figure 2). In an extension of this observation, the oncoprotein v-ErbA is shown here to have a greater requirement than TR for a chromatin target in effecting transcriptional repression.

\section{v-ErbA and TR associate with the corepressor $N-C o R$ and HDAC in the absence of Sin3, HDAC1/ RPD3 or Mi-2}

Our data are consistent with the hypothesis that HDAC activity targeted by chromatin-bound v-ErbA is respon- sible for effecting repression. Previous studies from this laboratory have proven the utility of the oocyte as a model system for biochemical characterization of protein complexes involved in transcriptional repression via histone deacetylation (Jones et al., 1998; Wade et al., 1998); such complexes are abundant in the oocyte, where they form a molecular stockpile in preparation for multiple rounds of early embryonic division. Since the only exogenous protein component in our transcription assays is the DNA-bound repressor, our findings indicate that the Xenopus oocyte contains sufficient quantities of auxiliary components of the repression pathway to allow the complete abolition of transcription driven by a DNA template that is $\sim 2$ orders of magnitude more abundant than the oocyte's own genome (1 ng of reporter plasmid 
DNA versus 12 pg of genomic DNA; Figure 1B, lanes 5 and 7).

We exploited a unique biochemical property of the $\mathrm{v}$-ErbA oncoprotein-the retroviral gag moiety on its $\mathrm{N}$-terminus-as a tool to investigate its protein partners in effecting TSA-sensitive transcriptional repression. We used mRNA microinjection to express v-ErbA in the oocyte and a monoclonal antibody directed against the gag epitope to demonstrate that a polypeptide of the expected size can be efficiently immunoprecipitated from whole oocyte extract (Figure 4A, lanes 4 and 5) under conditions of low to moderate ionic strength. Importantly for the interpretation of subsequent experiments, silver staining revealed a number of polypeptides that associated with the antibody in extracts from oocytes that were not injected with v-ErbA (Figure 4A, lanes 2 and 3). Proteins synthesized in the oocyte during the course of the experiment were labeled in vivo by $\left[{ }^{35} \mathrm{~S}\right]$ methionine, and autoradiographic analysis of the silver-stained Laemmli SDS-PAGE shown on the left in Figure 4A revealed that the predominant labeled species in the immunoprecipitation corresponds in size to the expected protein product of the v-ErbA mRNA (Figure 4A, lanes 9 and 10), and that no such entity was observed when no mRNA was injected (lanes 7 and 8). We conclude that the v-ErbA oncoprotein can be efficiently immunoprecipitated from whole oocyte extract.

An aliquot of this immunoprecipitate was analyzed by western blotting for the presence of proteins that interacted with the agarose-antibody complex in a v-ErbA-dependent manner. Following SDS-PAGE and transfer to a nitrocellulose membrane, autoradiographic analysis confirmed that the immunoprecipitation leads to a significant enrichment for target antigen in the precipitate (Figure 4B, top panel, lanes 5 and 6). We then used rabbit antisera against an N-terminal portion of Xenopus N-CoR (P.Jones, L.Sachs, N.Rouse and Y.-B.Shi, manuscript submitted) to reveal an extraordinary enrichment for this corepressor in immunoprecipitates from oocytes injected with v-ErbA (Figure 4B, second panel, lanes 5 and 6); we were reproducibly able to show that $>30 \%$ of all N-CoR contained in the input sample ( 30-60 oocyte equivalents of protein extract) associated with $\mathrm{v}$-ErbA under these conditions. Importantly, $<0.5 \%$ of N-CoR contained in the input associated with the beads in the absence of v-ErbA (Figure 4B, second panel, compare lane 1 with lanes 2 and 3 ), which was not an artefactual consequence of selective proteolysis or insufficient antibody used in the control reactions (Figure 4A, compare lanes 2 and 3 with 4 and 5). Further evidence for the specificity of the interaction lies in the reproducible finding that additional, lower molecular weight polypeptides contained in whole oocyte extract that react with the N-CoR antibody (identified by ' $-\mathrm{x}$ ' in the second panel of Figure 4B) fail to associate with v-ErbA (compare lanes 5 and 6 with lane 4 in Figure 4B).

Based on published observations (Heinzel et al., 1997), we assumed that the corepressor associated with v-ErbA in the oocyte targets the enzyme RPD3 (HDAC1) to the oncoprotein via the adapter molecule $\operatorname{Sin} 3$; to our surprise, however, no association between $\operatorname{Sin} 3$ and v-ErbA was observed. Data in lanes 5 and 6 in the second and third panels of Figure 4B show that the massive v-ErbAdependent enrichment for N-CoR in the immunoprecipi- tate is not accompanied by an enrichment for $\operatorname{Sin} 3$; background quantities ( $<1 \%$ input) of $\mathrm{Sin} 3$ protein associated with the antibody both in the presence and absence of v-ErbA (Figure 4B, compare lanes 2 and 3 with 5 and 6 ), indicative of a non-specific association that is likely to reflect the abundance of the Sin3 protein in oocytes (Vermaak et al., 1999). We also failed to observe an association between v-ErbA and either RPD3/HDAC1 (Figure 4B, fourth panel) or HDAC5 (Figure 4B, bottom panel). We performed a similar experiment in low ionic strength buffer $(5 \mathrm{mM} \mathrm{KCl}, 1.5 \mathrm{mM} \mathrm{MgCl} 2$ ) and failed to observe an association between v-ErbA and either Sin3, HDAC1, HDAC5 or RbAp48 under conditions of a robust $\mathrm{v}$-ErbA-dependent enrichment for $\mathrm{N}-\mathrm{CoR}$ (data not shown). HDAC did, however, associate with v-ErbA in our experiments, as shown by assaying the immunoprecipitate for HDAC activity using in vitro hyperacetylated histones as substrate (bottom of Figure 4B). While, as expected, both input samples efficiently released $\left[{ }^{3} \mathrm{H}\right]$ acetate from core histones (Figure 4B, bottom, lanes 1 and 4), immunoprecipitation of such activity was unequivocally dependent on v-ErbA (compare lanes 2 and 3 with 5 and 6 ). These data suggested that an entity other than HDAC1 or HDAC5 capable of deacetylating core histones associates with $\mathrm{v}$-ErbA in a manner that is independent of an enrichment for Sin3, and that such binding is accompanied by an interaction with N-CoR.

The utility of the gag moiety in enriching for v-ErbAdependent repression machinery components prompted us to expand its use to the parent molecule of v-ErbA, TR $\alpha$. In particular, we aimed to exploit the ligand responsiveness of TR as a transcriptional regulator (Figure 1B, lanes 5, 6, 7 and 8) to gauge the functional relevance of the biochemical interactions we observe with v-ErbA, which does not respond to ligand (Figure 1B). We used chicken TR $\alpha$ tagged with AEV gag on its N-terminus (Zenke et al., 1990) and confirmed that the tag does not in any detectable way alter the properties of TR as a transcriptional regulator in this system (Figure 4C, compare lanes 5 and 6 with 7 and 8$)$. We then used mRNA microinjection coupled with in vivo labeling by $\left[{ }^{35} \mathrm{~S}\right]$ methionine and immunoprecipitation with the anti-gag monoclonal antibody to confirm that gag-TR can be efficiently precipitated from whole oocyte extract (Figure 4D, lanes 3 and 4).

As expected from published observations (Heinzel et al., 1997) and our findings with v-ErbA (Figure 4B), TRdependent enrichment of N-CoR in the immunoprecipitate was observed under conditions of moderate ionic strength (45 mM NaCl, $5 \mathrm{mM} \mathrm{KCl,} 1.5 \mathrm{mM} \mathrm{MgCl}_{2}$; Figure 5B, middle panel, compare lanes 2 and 4). In an unexpected contradiction to published data that ligand-driven release of N-CoR from TR cannot be achieved in solution in the absence of DNA (Hoerlein et al., 1995), inclusion of $100 \mathrm{nM} \mathrm{T}_{3}$ in the oocyte culture medium and $1 \mu \mathrm{M} \mathrm{T}_{3}$ in the binding buffer and the wash solution reaction eliminated detectable N-CoR from the immunoprecipitate. The use of $\mathrm{T}_{3}$ reproducibly decreased by $\sim 1.5$-fold the amount of TR present in oocyte extract; we do not understand the biochemical basis of this effect (it is not due to homodimerization of unliganded $\mathrm{TR} \alpha$, as the same phenomenon was observed with TR $\beta$, which does not homodimerize in the unliganded state; data not shown), and hypothesize that it could result from a shorter half-life 
of the protein in the oocyte in the presence of ligand, or else a moderately lower extraction efficiency of liganded TR from whole extract. Importantly, however, even though the antigen targeted in the immunoprecipitation is $\sim 2$-fold less abundant in the presence than in the absence of hormone (compare lanes 4 and 6 in Figure 4D, top panel), $\mathrm{T}_{3}$ did not affect $\mathrm{N}-\mathrm{CoR}$ levels in the oocyte (compare lanes 3 and 5 in Figure 4D, second panel), and while $\sim 20 \%$ of input N-CoR associated with TR when no ligand was present (lane 4), no N-CoR could be detected in
A

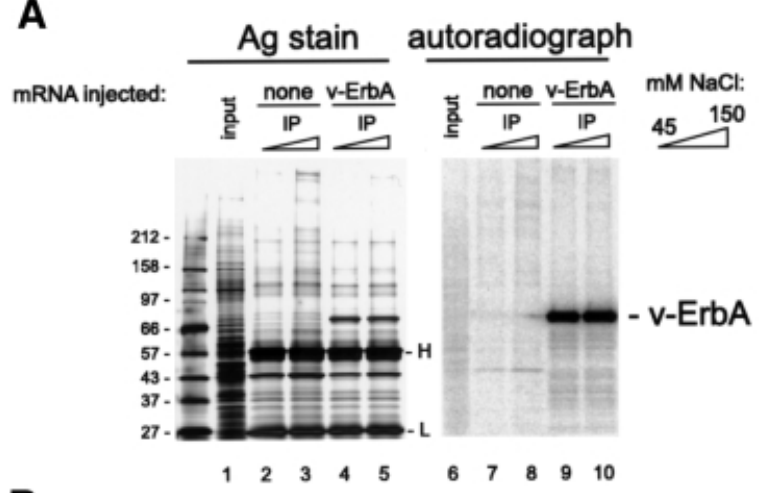

B

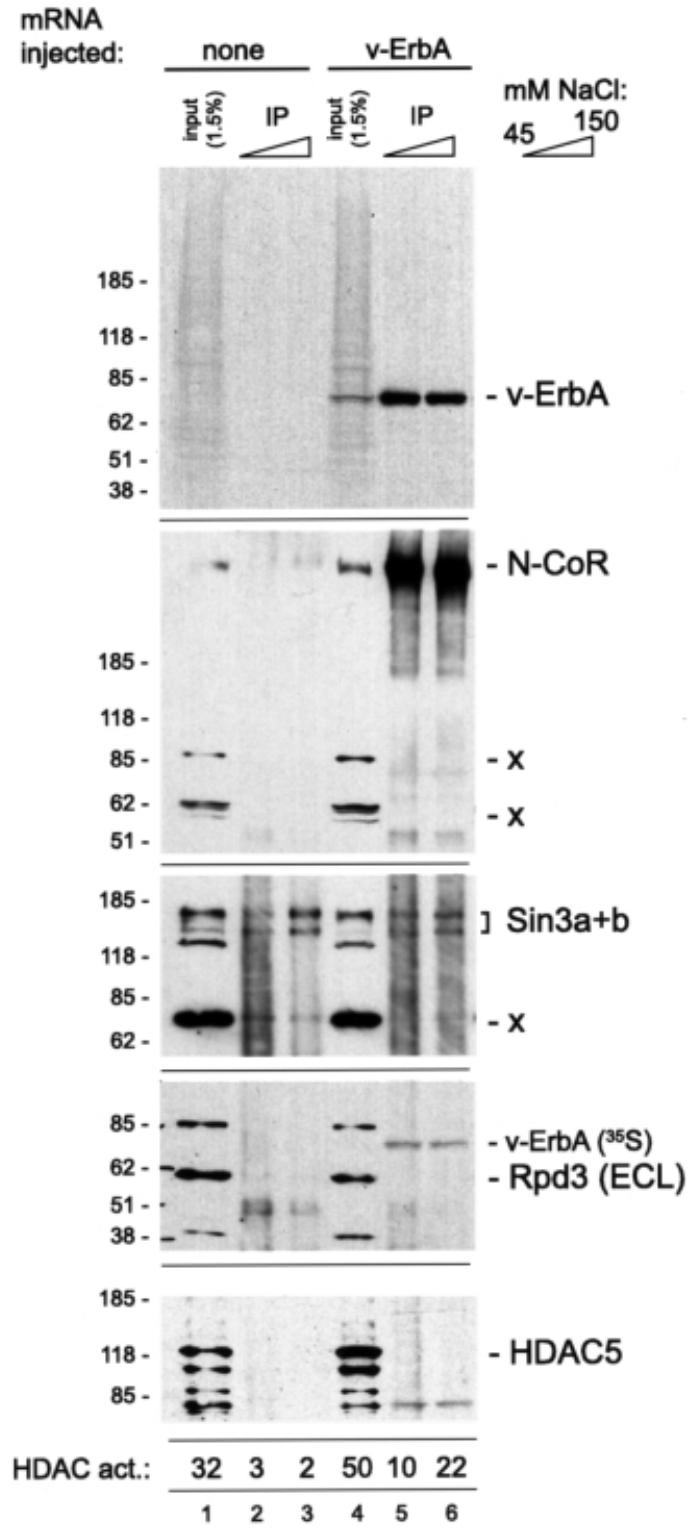

C

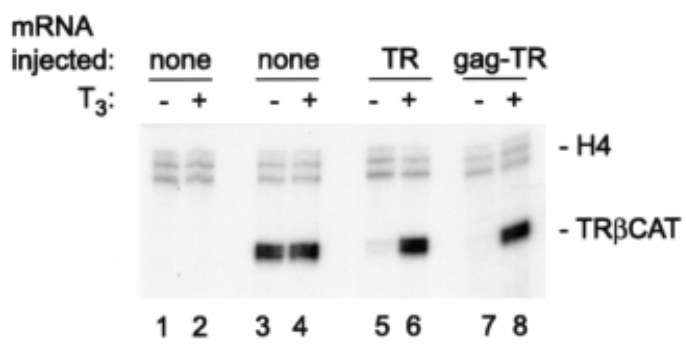

D mRNA
injected:

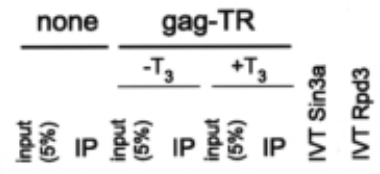

185 -

118 -

85 -

62 -

51 -

38 -

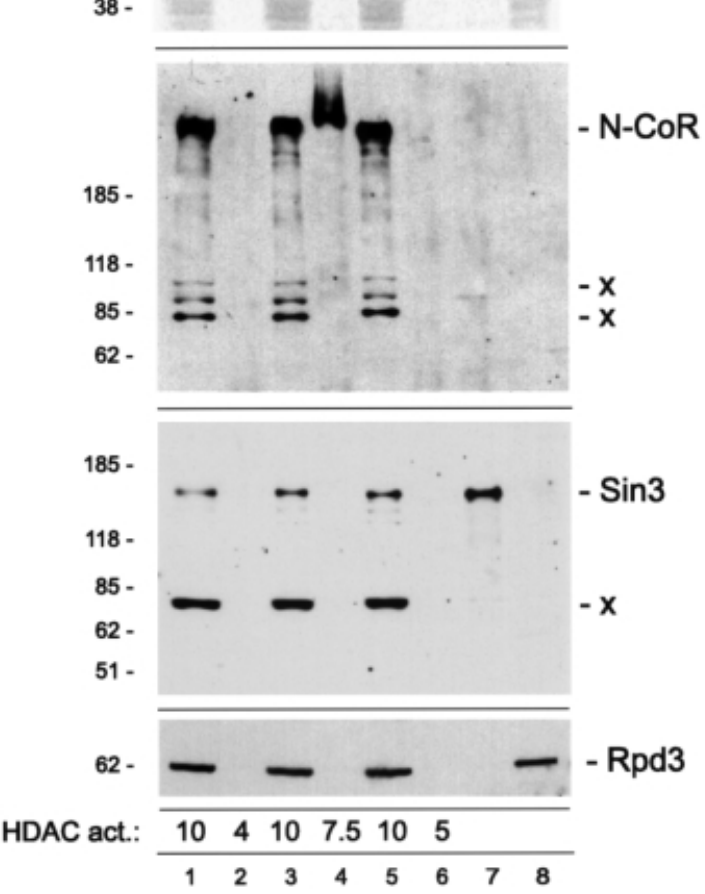


its presence (lane 6). We interpret these data as indicative of a robust ligand-regulated release of N-CoR by gag-TR in solution in the absence of a TRE.

In full agreement with our finding that an association between N-CoR and V-ErbA is not accompanied by the recruitment of Sin3 (Figure 4B), we failed (Figure 4D, third panel) to detect levels of Sin $3>0.5 \%$ of input in the immunoprecipitates that contained significant quantities of TR and N-CoR (Figure 4D, first and second panel, respectively). In addition, HDAC activity that associated with TR in this experiment (bottom of Figure 4D) was not due to a recruitment of RPD3/HDAC1(Figure 4D, lower panel), which was undetectable in the immunoprecipitate. We interpret these data to indicate that $\mathrm{v}$-ErbA and TR share a corepressor and HDAC recruitment pathway that does not involve an enrichment for the abundant proteins Sin3 or HDAC1.

To obviate concerns that sequential stripping and reprobing of the same membrane prevented the detection of Sin3 in the immunoprecipitate, or that the immunoreactive polypeptides shown in Figure $4 \mathrm{~B}$ and $\mathrm{D}$ do not represent Sin3, we reversed the order of probing. Samples from an immunoprecipitation experiment in which agarose-antibody-protein pellets were washed with increasing salt concentrations were subjected to western analysis with the Sin3 antibody (Figure 5A). Strong cross-reactivity of a polypeptide comigrating precisely with in vitro translated Sin3a (Vermak et al., 1999) shown in Figure 5A, lane 7 was observed in the input (lanes 1 and 3) but none of the immunoprecipitated samples (lanes 4-6). As confirmed by a longer exposure of the same membrane (Figure 5A, middle panel), the assay was sensitive to as little as $0.5 \%$ input $\mathrm{Sin} 3$; thus, under conditions of medium to high ionic strength, no meaningful quantity of Sin3 protein associates with v-ErbA. In contrast, robust $\mathrm{N}-\mathrm{CoR}$ recruitment to $\mathrm{v}$-ErbA was observed when this membrane was stripped and reprobed with an antibody against N-CoR (Figure 5A, lower panel, lanes 4-6).

Since both antigens used in the assay carried a retroviral gag domain on their N-terminus, it remained formally possible that the recruitment of N-CoR we observe was not physiological, but rather due to the gag moiety. To address this issue, we deleted the ligand-binding domain from gag$\mathrm{TR}$, and demonstrated by mRNA microinjection that the resulting gag-TR ${ }^{\mathrm{DBD}}$ fusion could be expressed in the oocyte and immunoprecipitated as efficiently as gag-TR (Figure 5B, top panel, lanes 3 and 4). Western blotting of the immunoprecipitate revealed a robust enrichment for $\mathrm{N}-\mathrm{CoR}$ in the presence of $\mathrm{v}$-ErbA (Figure 5B, second panel, lane 6) or gag-TR (lane 10), but not gag-TR ${ }^{\mathrm{DBD}}$. Thus, as expected, we show that the gag moiety does not contribute to corepressor recruitment. In addition, we sought to confirm that the unexpected ligand-driven release of corepressor from TR in solution (Figure 4D) was not an artefact; we immunoprecipitated v-ErbA in the presence of $\mathrm{T}_{3}$ (Figure 5B, top panel, lanes 7 and 8) and showed its continued association with $\mathrm{N}-\mathrm{CoR}$ (middle panel, lanes 7 and 8) under conditions where no detectable N-CoR associated with liganded TR (middle panel, lanes 11 and 12). Finally, we used immunoblotting against the Mi-2 protein (Wade et al., 1998) to demonstrate that no detectable quantities of this exceedingly abundant ATPase associated with TR or V-ErbA (bottom panel) under conditions of robust N-CoR recruitment (second panel); we note that in this assay, as little as $0.1 \%$ input Mi-2 could be detected, and none of it bound to TR.

We interpret these data to indicate that the ligandbinding domain of TR and $\mathrm{v}$-ErbA is competent for the targeting of corepressor and HDAC activity, and that such targeting - regulated by ligand in the case of TR but not in the case of $\mathrm{v}$-ErbA - is not accompanied by recruitment of

\footnotetext{
Fig. 4. A biochemical analysis of associations of the v-ErbA oncoprotein in the oocyte. (A) v-ErbA can be immunoprecipitated from whole oocyte extract using a monoclonal antibody against the gag domain. Oocytes (100 per sample) were left uninjected (lanes 1-3 and 6-8) or injected with $10 \mathrm{ng}$ of mRNA for v-ErbA (lanes 4, 5, 9 and 10) and cultured in the presence of $\left.{ }^{35} \mathrm{~S}\right]$ methionine for $16 \mathrm{~h}$; immunoprecipitation with anti-gag monoclonal antibody was performed as described in Materials and methods in $45 \mathrm{mM} \mathrm{NaCl}$-containing buffer, followed by washing in buffer containing the amount of $\mathrm{NaCl}$ indicated on the right. One third of the immunoprecipitate was resolved on a 4-12\% Laemmli SDS-PAGE followed by silver staining (lanes 1-5) and autoradiographic analysis of the silver-stained gel (lanes 6-10). The 'input' lane contains 1/20 of an oocyte equivalent of whole oocyte protein extract; the position of molecular weight markers is indicated to the left of the gel, the v-ErbA-sized polypeptide-to the right of the gel, and of immunoglobulin light $(\mathrm{L})$ and heavy $(\mathrm{H})$ chain - between lanes 5 and 6. (B) Recruitment of N-CoR and HDAC activity to v-ErbA is not accompanied by an enrichment for Sin3, HDAC1 or 5. One third of the immunoprecipitate described in the legend to (A) was resolved on a 4-12\% Laemmli SDS-PAGE along with the indicated quantity of input whole oocyte extract, transferred to a nitrocellulose membrane and analyzed by autoradiography (top panel) and sequential western blotting with antibody against Xenopus N-CoR (second panel), Sin3 (third panel), Rpd3p/HDAC1 (fourth panel) and mouse HDAC5 (fifth panel). In all panels, the position of molecular weight markers is indicated to the right, and the position of the antigen targeted by the antibody is to the left of the autoradiograph. The positions of additional polypeptides that cross-react with the antibodies are indicated by $-\mathrm{x}$; longer ( 5-10 $\mathrm{min})$ exposures to X-ray film used in the fourth and fifth panels reveal a band corresponding precisely to the ${ }^{35}$ S-labeled v-ErbA polypeptide along with the chemiluminescence (ECL)-derived signal from the target antigen. The numbers below the fifth panel were obtained by measuring HDAC activity in the remaining 1/3 of the immunoprecipitate exactly as described (Wade et al., 1999b) and expressing the resulting values in arbitrary units relative to a blank sample. (C) The gag tag does not affect the properties of TR as a transcriptional regulator of the Xenopus TR $\beta$ A gene. Oocytes were injected with mRNA for Xenopus RXR $\alpha$ (lanes 5-8) along with mRNA chicken TR $\alpha$ (lanes 5 and 6 ) or chicken TR $\alpha$ tagged with the AEV gag moiety on its N-terminus (lanes 7 and 8), followed by injection of $1 \mathrm{ng}$ of double-stranded TR $\beta A$ reporter DNA (lanes 3-8) and analysis of transcription by primer extension as described in the legend to Figure 1B. (D) Ligand-regulated recruitment to TR of $\mathrm{N}-\mathrm{CoR}$ and HDAC activity is not accompanied by an enrichment for Sin3 or HDAC1/RPD3. Sixty oocytes were left uninjected (lanes 1 and 2), or injected with $10 \mathrm{ng}$ of mRNA for gag-tagged chicken TR $\alpha$ (lanes 3-6) and cultured in $\left.{ }^{35} \mathrm{~S}\right]$ methionine-containing medium in the presence or absence of $100 \mathrm{nM} \mathrm{T}_{3}$, as indicated. Immunoprecipitation with antibody against gag was performed as described in (B); binding and washing was performed in $45 \mathrm{mM} \mathrm{NaCl}$ and $1 \mu \mathrm{M} \mathrm{T}_{3}$ where indicated. An aliquot of the immunoprecipitate along with the indicated quantity of input extract and an aliquot of in vitro translated Xenopus Sin3 (lane 7) was resolved on a 4-12\% Laemmli SDS-PAGE, transferred to nitrocellulose and analyzed by autoradiography (top panel; quantitation of the gag-TR signal reveals a 2-fold greater amount in lane 4 as compared with lane 6) and by western blotting with antibody against N-CoR (middle panel) and Sin3 (bottom panel). An identical immunoprecipitation was split into two aliquots, and one was analyzed by western blotting as above with an antibody against RPD3 (bottom panel), while the other was assayed for HDAC activity as above.
} 
A

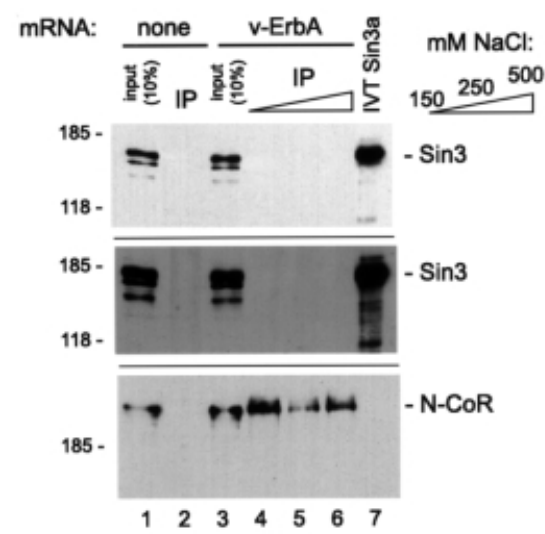

B

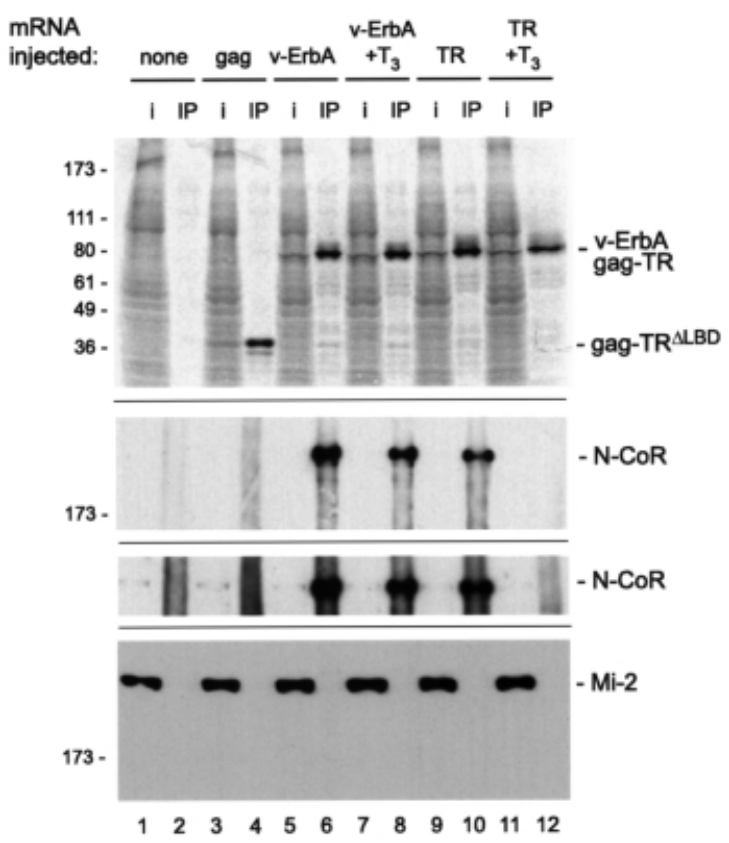

Fig. 5. Further characterization of N-CoR/HDAC enrichment by v-ErbA and TR. (A) Immunoprecipitation from 100 uninjected oocytes (lane 2) or oocytes injected with v-ErbA mRNA (lanes 4-6) was performed as described above, except the binding buffer contained $95 \mathrm{mM} \mathrm{NaCl}$ (final concentration of monovalent cations in the reaction $=100 \mathrm{mM}$ ), and the washing was performed with buffer containing $\mathrm{NaCl}$ at the concentration indicated to the right of the gel (100 mM for lane 2). One sixth of the sample was resolved on a 6\% Laemmli SDS-PAGE along with the indicated quantity of input whole oocyte extract (lanes 1 and 3) and an aliquot of in vitro translated Xenopus Sin3 (lane 7). Western blotting was performed with antibody against Sin3 (top two panels; these represent two different exposures of the same membrane), followed by stripping and reprobing with an antibody for N-CoR (bottom panel). (B) The gag moiety fails to recruit $\mathrm{N}$-CoR, and ligand fails to eliminate $\mathrm{N}$-CoR from v-ErbA. Oocytes were left uninjected (lanes 1 and 2), injected with an mRNA representing gag-tagged TR with the entire ligand-binding domain deleted (lanes 3 and 4), v-ErbA (lanes 5-8) or gag-TR (lanes 9-12), and cultured in medium containing $\left[{ }^{35} \mathrm{~S}\right]$ methionine. Following immunoprecipitation in $50 \mathrm{mM} \mathrm{NaCl}$ in the absence or presence of $1 \mu \mathrm{M} \mathrm{T}_{3}$ (as indicated) with anti-gag antibody, one half of the immunoprecipitate was resolved on a 4-20\% PAGE and autoradiographed (top panel), while the other half was resolved on a 6\% PAGE and immunoblotted with antibody against $\mathrm{N}-\mathrm{CoR}$ (second and third panel; the lower of the two represents a longer exposure of the upper, included to demonstrate $\mathrm{N}-\mathrm{CoR}$ in all the input samples) and Mi-2 (lower panel). Lanes labeled 'i' contain 1\% input protein.
RPD3/HDAC1 in any biochemical form, either free or associated with the adapter molecule Sin3 (Heinzel et al., 1997) or the Mi-2 ATPase (Xue et al., 1998).

\section{$v$-ErbA and TR associate with the corepressor $N-C o R$ and HDAC3}

Since HDAC activity, but no HDAC1 or HDAC5 could be detected in the immunoprecipitates of v-ErbA and TR (Figure 4), we sought to identify this HDAC using commercially available antibodies against other HDACs. To that end, we used an antibody against HDAC3 (Yang et al., 1997; Dangond et al., 1998; Emiliani et al., 1998), a class I HDAC related to, but distinct from, HDAC1/RPD3, to assay for its potential targeting. As shown in Figure 6A, enrichment for N-CoR occurred only in the presence of TR and in the absence of ligand (top panel, lane 3). This interaction was accompanied by an extraordinary enrichment for HDAC3 (Figure 6A, middle panel, compare lanes 1 and 3); it was dependent on TR (lane 2) and exceptionally sensitive to ligand (compare lanes 3 and 4). In full agreement with previous observations (Figure 4D), no detectable HDAC1/RPD3 associated with TR (bottom panel).

To substantiate our discovery of HDAC 3 targeting to TR, we sought to extend this observation to v-ErbA. As shown in Figure 6B (middle panel), v-ErbA-dependent enrichment for $\mathrm{N}-\mathrm{CoR}$ from whole oocyte extract occurred even in $0.5 \mathrm{M} \mathrm{NaCl}$ (lane 6), and this recruitment was accompanied by a v-ErbA-dependent enrichment for HDAC3 (bottom panel, compare lane 2 with lanes 4-6) that was equally salt resistant (lane 6).

We hypothesized that the corepressor acts as an adapter molecule that bridges TR/v-ErbA with HDAC3. If that were the case, one would expect N-CoR and HDAC 3 to associate biochemically. To investigate this issue, we performed immunoprecipitations from egg extract with an antibody against N-CoR and showed a significant enrichment for HDAC3 that was unambiguously dependent on N-CoR-reactive idiotypes in the serum (Figure 6C, compare lanes 6 and 7), since pre-immunization serum failed to enrich for HDAC3 (compare lanes 3 and 6).

These data suggest that a major contribution to the HDAC activity found enriched by TR and v-ErbA can be attributed to the recruitment of HDAC3, and, further, that the corepressor $\mathrm{N}-\mathrm{CoR}$ and $\mathrm{HDAC} 3$ can associate with the v-ErbA oncoprotein under stringent conditions. Finally, the association between $\mathrm{N}-\mathrm{CoR}$ and $\mathrm{HDAC} 3$ suggests that the corepressor acts to bridge unliganded receptor and HDAC.

\section{Distinct pattern of interactions by TR and v-ErbA with components of the basal transcriptional machinery}

While corepressor-mediated HDAC recruitment by TR and v-ErbA is likely to contribute to receptor-effected transcriptional repression, both proteins appear to be equally competent for that recruitment (Figures $4 \mathrm{~B}$ and D, and $6 \mathrm{~A}$ and $\mathrm{B}$ ). We hypothesized, therefore, that the distinct requirements for template chromatin assembly in effecting repression (Figure 3C) might be the consequence of an impairment of the v-ErbA protein in exploiting a pathway for repression auxiliary to N-CoR and HDAC targeting. 
A

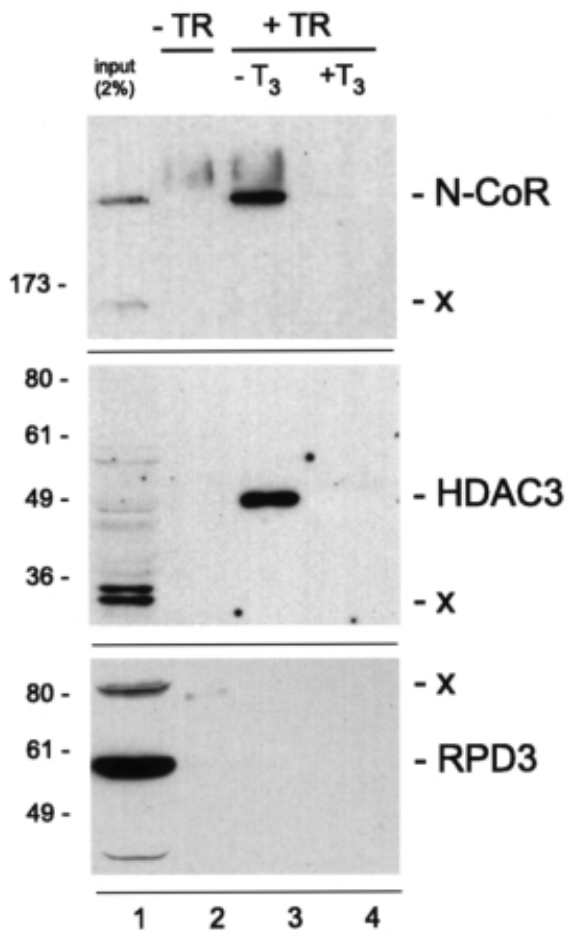

B
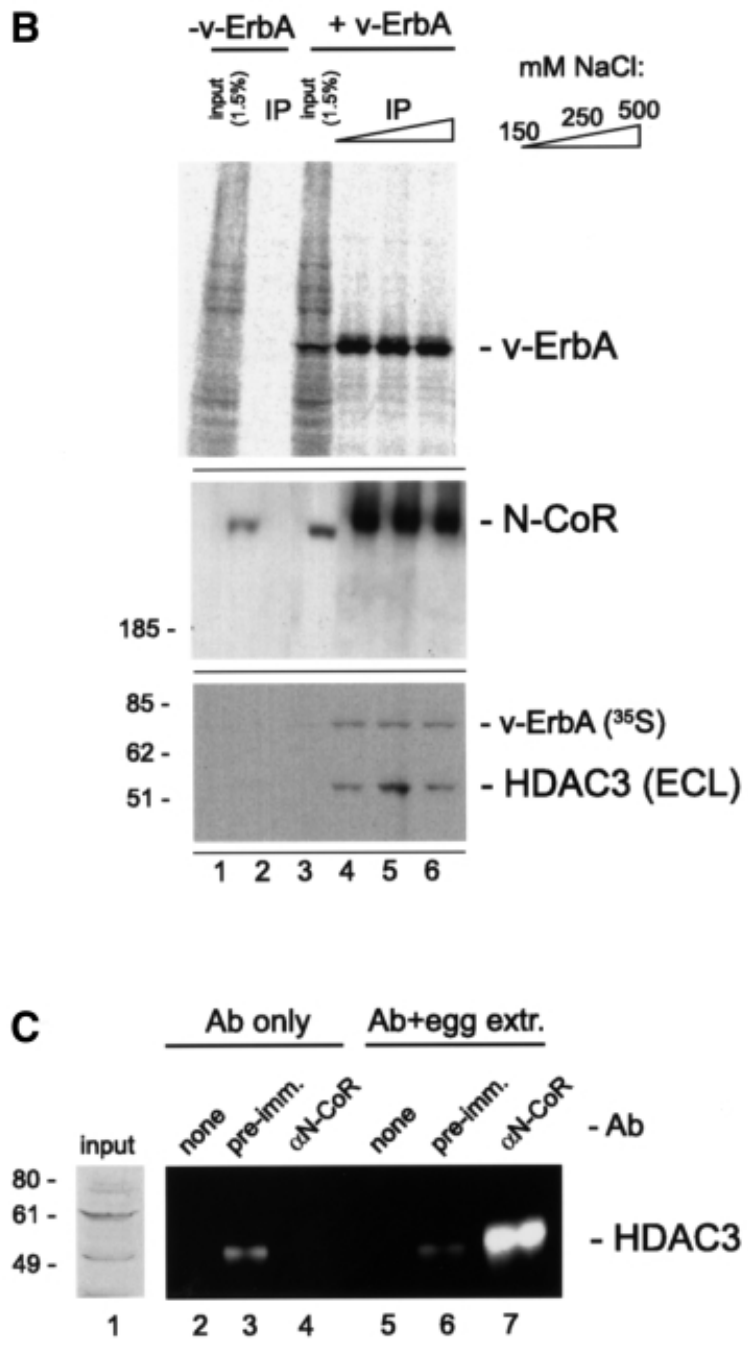

Studies of silencing by TR in a biochemically defined in vitro transcription system with purified DNA templates implicated binding by TR to components of the basal machinery such as TBP and TFIIB in mediating repression (Fondell et al., 1993, 1996). In addition, however, more recent data (Muscat et al., 1998; Wong and Privalsky, 1998) have suggested that a functional interaction between the corepressors N-CoR/SMRT and TFIIB might play a similar role. We asked whether the distinct transcription silencing properties exhibited by v-ErbA as compared with TR - the dependence on chromatin for silencing and a greater sensitivity to HDAC inhibitors-can be correlated with a hypothetical deficiency in v-ErbA interactions with the basal transcriptional machinery.

We used recombinant TBP and TFIIB fused to glutathione $S$-transferase (GST) (Figure 7A) in an in vitro assay for their ability to interact with chicken TR and v-ErbA. As shown in Figure 7B and C, lanes 1-4, chicken TR interacted with both proteins; in precise agreement with published observations (Tone et al., 1994; Fondell et al., 1996), the TR-TBP interaction was adversely affected by addition of ligand (Figure 7B, lane 4), whereas TR and TFIIB interacted ligand independently (Figure 7C, lane 4).

Figure 7B, lanes 5-8 shows that v-ErbA bound to GSTTBP; we note that this interaction was resistant to $0.5 \mathrm{M}$ $\mathrm{NaCl}$ and $0.1 \% \mathrm{NP}-40$, as well as treatment with ligand. In contrast, as shown in Figure 7C, lanes 5-8, under identical conditions, v-ErbA failed to bind to GST-TFIIB at levels above background binding to GST (lanes 6-8). In

Fig. 6. TR and v-ErbA recruit HDAC3. (A) TR enriches for N-CoR and HDAC3, but not RPD3. A large aliquot of Xenopus egg extract was adjusted to $50 \mathrm{mM} \mathrm{NaCl}$ and $0.1 \% \mathrm{NP}-40$ and incubated with a preparation of bead-immobilized GST-TR (lanes 3 and 4) or GST (lane 2). Where indicated, $2.5 \mu \mathrm{M} \mathrm{T}_{3}$ was included in the reaction. Following washing as described in Figure 4D, proteins associated with the beads were analyzed by immunoblotting against N-CoR (top panel), HDAC3 (middle panel) and RPD3 (bottom panel). (B) v-ErbAdependent enrichment for $\mathrm{N}-\mathrm{CoR}$ in the immunoprecipitate is accompanied by an enrichment for HDAC3. One half of the immunoprecipitate described in the legend to Figure 5A was resolved on a 4-12\% Laemmli SDS-PAGE, and analyzed by autoradiography (top panel) and western blotting with antibody against N-CoR (middle panel) and human HDAC3 (bottom panel). As in Figure 4B, the longer $(10 \mathrm{~min})$ exposure used in the bottom panel reveals both the ${ }^{35} \mathrm{~S}$-labeled antigen directly targeted in the immunoprecipitation as well as chemiluminescence-derived signal from the antibody used in the western blot. Low efficiency of the anti-HDAC 3 antibody prevents the visualization of HDAC 3 in the 0.5 oocyte equivalents of extract used in the input lanes (lanes 1 and 3). (C) N-CoR and HDAC3 co-immunoprecipitate. A preparation of bead-immobilized rabbit antiserum against $\mathrm{N}-\mathrm{CoR}$ (lanes 4 and 7), the cognate pre-immunization serum (lanes 3 and 6) or the beads with no antibody (lanes 2 and 5) was incubated in Xenopus egg extract adjusted to $50 \mathrm{mM} \mathrm{NaCl}$ and $0.1 \% \mathrm{NP}-40$. The proteins associating with the antibody were eluted with glycine and analyzed for the presence of HDAC3 by immunoblotting with rabbitderived anti-HDAC 3 serum and extended duration ECL reagents, followed by visualization and quantitation on a CCD camera-equipped ChemiImager-4400 low light imaging system. The small amount of rabbit anti-N-CoR antibody released from the beads (lanes 2-4) yields Ig heavy chain signal at $50 \mathrm{kDa}$ (lanes 2-4), i.e. at the molecular weight of HDAC3; quantitation indicates a 60-fold greater signal in lane 7 (anti-N-CoR antibody + egg extract) than in lane 4 (anti-N-CoR antibody only). Lane 1 contains an aliquot of egg extract analyzed on the same gel and probed with conventional ECL reagents, followed by autoradiography. 
additional experiments we found that GST-TFIIB was susceptible to proteolysis in bacterial cells used for its generation (data not shown), and that preparations of GST-TFIIB proteolysed to a greater extent than the one shown in Figure 7A, lane 3, exhibited moderate binding to

A

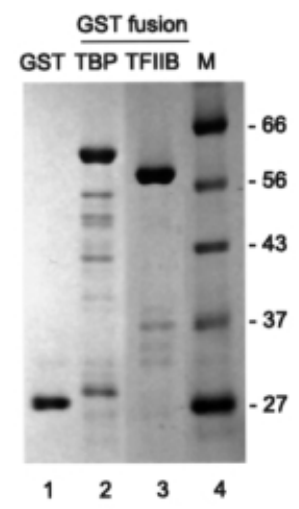

B

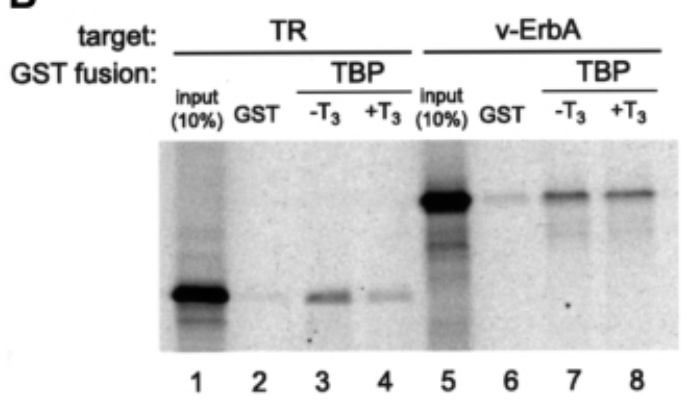

C

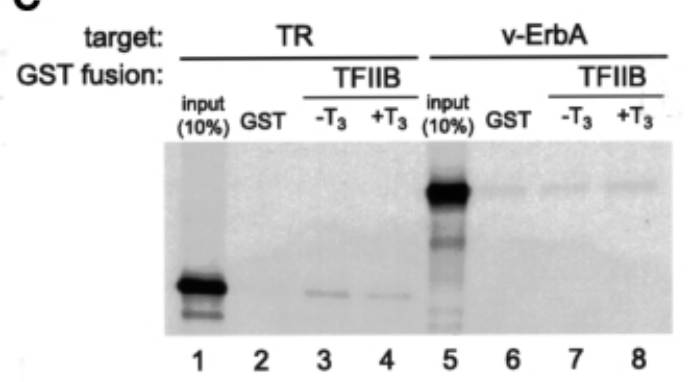

D

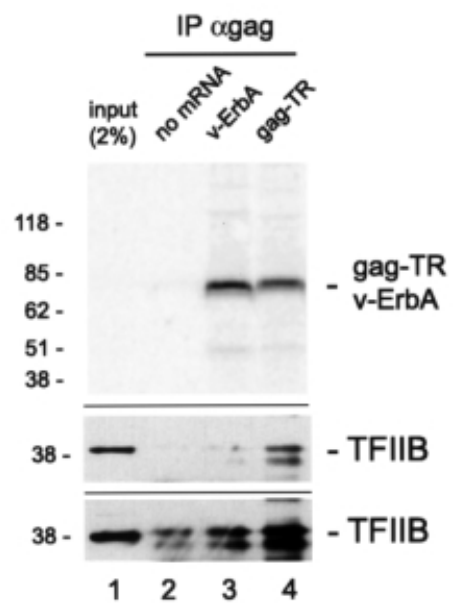

v-ErbA (data not shown)—most likely a consequence of the biochemical 'stickiness' of partial-length GST-TFIIB fragments.

To resolve conclusively the matter of $\mathrm{v}$-ErbA/TRTFIIB interaction, we investigated this issue in vivo. We injected v-ErbA and gag-TR mRNA into the oocyte and used immunoprecipitation under conditions of low stringency $(5 \mathrm{mM} \mathrm{NaCl}, 5 \mathrm{mM} \mathrm{KCl}, 1.5 \mathrm{mM} \mathrm{MgCl} 2,0.05 \%$ NP-40) to assay for potential TFIIB enrichment. We were able to reveal reproducibly a greater amount of TFIIB targeted to TR (Figure 7D, middle panel, lane 4) than to the antibody alone (lane 2) or to v-ErbA (lane 3). This preference for TR over $\mathrm{V}$-ErbA was not a consequence of insufficient TFIIB in the oocyte, as experiments carried out under conditions of $\sim 5$-fold overexpression of TFIIB yielded the same result (data not shown). We note, however, that only a small fraction $(\sim 2 \%)$ of input TFIIB is bound by TR and $\mathrm{v}$-ErbA under conditions of extraordinary enrichment for N-CoR by both proteins (Figure 4B and D), suggesting that direct binding of TR to TFIIB, rather than interactions via corepressor (Muscat et al., 1998; Wong and Privalsky, 1998), may occur in vivo.

These experiments aimed to reveal a biochemical correlate to our observations that v-ErbA, but not TR, fails to silence transcription on partly chromatinized DNA. We find that while v-ErbA can bind to TBP as efficiently as TR (Figure 7B), the former protein is moderately impaired in its ability to bind TFIIB in vitro (Figure 7C) and in vivo (Figure 7D).

\section{Discussion}

\section{A pathway of repression by targeting N-CoR- HDAC3 to v-ErbA and TR}

Unliganded TR is a remarkably efficient repressor of basal transcription in Xenopus (Wong et al., 1995), comparable in potency only to the extraordinarily rapid methylationcoupled transcriptional repression pathways also operating

Fig. 7. In vitro and in vivo assays for the ability of TR and v-ErbA to interact with components of the basal transcription machinery. (A) A preparation of glutathione-Sepharose beads attached to GST (lane 1), GST-TBP (lane 2) or GST-TFIIB (lane 3) was boiled in Laemmli SDS-PAGE loading buffer, electrophoresed, and the recombinant proteins visualized by Coomassie Brilliant Blue staining. Lane ' $M$ ' contains molecular weight markers the sizes of which are indicated to the right of the gel. (B) Equimolar quantities of reticulocyte-lysatetranslated TR (lanes 1-4) or v-ErbA (lanes 5-8) were mixed with beads fused to GST (lanes 2 and 6) or GST-TBP (lanes 3, 4, 7 and 8). T 3 was included at $1 \mu \mathrm{M}$ where indicated. Following incubation and washing in buffer containing $0.5 \mathrm{M} \mathrm{NaCl}$ and $0.1 \% \mathrm{NP}-40$, the proteins bound to the beads were eluted and analyzed by SDS-PAGE and autoradiography. The 'input' lanes contain $1 / 10$ of the total protein used in each reaction. (C) The ability of TR (lanes 1-4) and v-ErbA (lanes 5-8) to bind GST-TFIIB was assayed exactly as described in the legend to (B). (D) v-ErbA exhibits a moderate impairment in binding to TFIIB in vivo. Oocytes were left uninjected (lane 2) or injected with mRNA for v-ErbA (lane 3) or gag-TR (lane 4); the injected oocytes were cultured in $\left[{ }^{35} \mathrm{~S}\right]$ methionine-containing medium. Immunoprecipitation with antibody against gag was performed as described in Figure 4B, except the binding and washing buffers contained $5 \mathrm{mM}$ $\mathrm{NaCl}$ and $5 \mathrm{mM} \mathrm{KCl}$. The entire immunoprecipitate was resolved on a 4-12\% Laemmli SDS-PAGE along with the indicated quantity of input extract and analyzed by autoradiography (top panel) and western blotting against TFIIB (the middle and lower panels represent different exposures of the same membrane). 
in the oocyte (Kass et al., 1997). Earlier work had suggested that histone deacetylation may contribute to repression by TR (Wong et al., 1997), and that auxiliary pathways may exist. The present study begins their functional dissection using a mutated version of TR, the oncoprotein v-ErbA.

Our data are consistent with previous models implicating HDAC-associated corepressors in repression by unliganded TR (Heinzel et al., 1997; Nagy et al., 1997). Evidence for a functional relationship between N-CoR recruitment and TR-effected repression in this system comes from the precise correlation between effects of ligand on transcription in the presence of TR (Figure 1B) and on association with N-CoR (Figures 4D and 6A) and HDAC3 (Figure 6A). A previous study (Hoerlein et al., 1995 ) indicated that $T_{3}$ fails to release $\mathrm{N}-\mathrm{CoR}$ from TR unless the latter is bound to DNA. In contrast, we report here the robust disruptive effect of ligand on the interaction between $\mathrm{N}-\mathrm{CoR}$ endogenous to the oocyte and ectopically introduced TR in the absence of a TRE (Figures 4D, 5B and 6A). It is possible that the more extensive regimen of treatment with $\mathrm{T}_{3}$ in the present study, as well as our reliance on endogenous N-CoR rather than overexpressed $\mathrm{N}-\mathrm{CoR}$ as used by Hoerlein et al. (1995) contributed to this difference.

Our biochemical analysis yielded the unexpected observation that the large quantity of endogenous N-CoR recruited to v-ErbA (Figure 4B) and to TR (Figure 4D) is not associated with $\operatorname{Sin} 3$. In addition, we show that an enrichment for HDAC activity and HDAC3 via N-CoR occurs without an association with HDAC1/RPD3 or Sin3 (Figure 4). Since TR and v-ErbA exhibit robust repression function in the oocyte (Figure 1C) and associate with N-CoR without engaging Sin3 or RPD3 (Figures 4 and 5), we suggest that a pathway for repression via an N-CoR/ SMRT-Sin3-HDAC1 complex (Heinzel et al., 1997; Nagy et al., 1997) is not exploited by TR or by v-ErbA in Xenopus.

It is important to note that in Xenopus a Sin3-containing complex targets HDAC to methylated DNA via the transcriptional repressor $\mathrm{MeCP} 2$ to effect methylationdependent transcriptional silencing (Jones et al., 1998), and that the HDAC RPD3 is contained in an exceedingly abundant complex with the Mi-2 ATPase (Wade et al., 1998). Both Sin 3 and RPD3, therefore, are present in sufficient quantities to accommodate an interaction with $\mathrm{N}-\mathrm{CoR}$, and, in fact, our data do not address the possibility of the existence of such a complex in the oocyte, but do argue against the possibility that such a complex mediates transcriptional repression by $\mathrm{v}$-ErbA and by unliganded chicken TR. We also note that while a major form of HDAC in the oocyte is represented by the six-subunit Mi-2 complex (Wade et al., 1998), the lack of targeting of its three core components, HDAC1, Mi-2 or RbAp48, to unliganded TR (Figures 4D and 5B), which occurs while significant amounts of N-CoR and HDAC3 are bound by TR, strongly argues against a previously hypothesized (Xue et al., 1998) role for the Mi-2 complex in TReffected repression.

Figure 4 shows that the recruitment of HDAC activity to $\mathrm{v}$-ErbA is accompanied by an enrichment for the class I deacetylase HDAC3, the third ortholog in metazoa of the budding yeast HDAC Rpd3p (Yang et al., 1997; Dangond et al., 1998; Emiliani et al., 1998). Its identification in association with v-ErbA and N-CoR in the absence of Sin3 and HDAC1 is consistent with its lack of interaction with Sin3 in vitro (Emiliani et al., 1998) and the failure to reveal the corepressors N-CoR and SMRT in Sin3containing complexes (Hassig et al., 1997; Zhang et al., 1997). Our data do not exclude the possibility that additional HDACs other than HDAC1 or -5 associate with v-ErbA-N-CoR. Recent studies revealed that a novel HDAC associates with the corepressor SMRT (Kao et al., 2000 ), and that $\sim 2 \%$ of endogenous N-CoR in $293 \mathrm{~T}$ cells associates with HDAC4 (Huang et al., 2000), one of several recently identified metazoan orthologs of the yeast HDAC Hda1p. Neither of these two studies, however, addressed the issue of whether these associations contribute to transcriptional repression by NHRs. The observation that the corepressors N-CoR and SMRT interact with HDAC5 in yeast two-hybrid assays (Huang et al., 2000; Kao et al., 2000) prompted us to investigate whether such a complex might contribute to repression by v-ErbA in Xenopus, but we failed to observe an association of HDAC5 with v-ErbA-targeted N-CoR (Figure 4B).

The functional utility to the cell of multiple enzymes that perform the same reaction of histone tail deacetylation remains unclear. In this regard, it is curious that when assayed in the context of a hyperacetylated nucleosome, HDAC3 was reported to be more robust than HDACs 1 or 2 in deacetylating histone H4 (Emiliani et al., 1998). Diacetylated histone $\mathrm{H} 4$ is deposited onto DNA during de novo chromatin assembly in $\mathrm{S}$ phase, with deacetylation occurring over $\sim 30$ subsequent minutes (Shimamura and Worcel, 1989; Ura et al., 1997; Adams and Kamakaka, 1999). In Xenopus, inhibition of HDAC activity during chromatin assembly greatly stimulates transcription of the TR $\beta$ A promoter (Figure 2), as does overexpression of Sin3 in the oocyte (Vermaak et al., 1999), presumably via cytoplasmic sequestration of a Sin3-associated HDAC. Taken together, these observations support the earlier hypothesis that HDAC1/RPD3 mediates assemblycoupled deacetylation of histone H4 (Rundlett et al., 1996) and open the possibility that during chromatin assembly, HDAC3 targeted by v-ErbA (Figure 4) or TR (Figure 6) to specific loci might accelerate this deacetylation relative to other sites in the genome and promote the generation of a repressive chromatin structure. Indeed, we have previously reported that unliganded TR is most effective in repressing transcription during replicative chromatin assembly (Wong et al., 1995, 1998b). The Xenopus oocyte system is well suited to investigating the possibility of accelerated deacetylation being targeted by unliganded TR and v-ErbA.

\section{A requirement for chromatin infrastructure in repression by v-ErbA-N-CoR-HDAC3 and auxiliary pathways in repression by TR}

The present study revealed two unexpected differences between TR and $\mathrm{v}$-ErbA as transcriptional regulators of the TR $\beta A$ gene: first, the former protein can repress basal transcription at all states of target template chromatinization, while the efficiency of the latter as a transcriptional repressor is positively correlated with the extent of the assembly of its target into chromatin (Figure 3); secondly, the HDAC inhibitor TSA stimulates a promoter repressed 
by $\mathrm{v}$-ErbA to a much greater extent than a promoter repressed by TR. These observations shed new light on (i) the previous finding that the Xenopus HDAC RPD3 requires a greater extent of template chromatinization than does unliganded TR to effect repression (Wong et al., 1997) and (ii) on our observation that TR and v-ErbA both complex with N-CoR-HDAC3 (Figure 6). These findings are fully consistent with the hypothesis that some feature of a chromatin template-perhaps overall nucleosome density, or some other structural parameter acquired during in vivo chromatin maturation-is required to allow both targeted or philandering HDAC to effect repression. Thus, we propose that recruitment of the N-CoR-HDAC3 corepressor complex represents the chromatin-dependent component of repression effected by unliganded TR, and that $\mathrm{v}$-ErbA relies on such recruitment to effect repression to a greater extent than TR. This latter suggestion stems from three observations: (i) the capacity of TSA to relieve most of the repression effected by v-ErbA (compare lanes 3 and 16 in Figure 2B); (ii) the nearly identical requirements that overexpressed HDAC and v-ErbA have for template chromatinization in effecting repression (present study and Wong et al., 1997); and (iii) the finding that a v-ErbA mutant known to be impaired in corepressor recruitment (Chen and Evans, $1995)$ is also impaired in silencing in the oocyte system (J.Yee, F.D.Urnov and A.P.Wolffe, unpublished), while TR carrying the cognate mutation is competent for repression (T.N.Collingwood and A.P.Wolffe, unpublished).

What evidence, then, can be provided for the existence of auxiliary pathways in repression by TR, and how can one explain the impairment exhibited by $\mathrm{v}$-ErbA in exploiting these pathways? As shown in Figure 2B, global inhibition of HDAC activity via TSA treatment during chromatin assembly strongly activates basal transcription driven by the TR $\beta$ A promoter (compare lanes 2 and 3). When the promoter is bound by unliganded TR, however, TSA relieves repression to only a fraction of the level seen in the absence of receptor (Figure 2B, compare lanes 3 and 11). The same phenomenon is observed if chromatin is allowed to mature in the absence of an HDAC inhibitor: the capacity of TSA to activate transcription from a mature chromatin template is markedly reduced by TR bound to the promoter (Figure 2B, compare lanes 4 and 5 with 13 and 14). These findings are inconsistent with the notion that HDAC targeting accounts for the entirety of transcriptional repression effected by TR.

It is instructive to compare our data with observations from studies of other HDAC-recruiting transcriptional repressors. For instance, TSA only partly relieves repression mediated by the Drosophila repressor groucho (Chen et al., 1999), and genetic data suggest that pathways additional to HDAC $1 / \mathrm{Rpd} 3 \mathrm{p}$ recruitment are exploited by this repressor (Mannervik and Levine, 1999). Similarly, repression by the retinoblastoma protein-associated corepressor RBP1 is thought to be effected via both HDAC-dependent and -independent mechanisms, and, accordingly, TSA fails to alleviate fully repression mediated by RBP1 (Luo et al., 1998; Lai et al., 1999). While there is no in vivo functional evidence regarding the mechanisms responsible for the operation of such auxiliary pathways, data from Roeder and coworkers obtained using in vitro assays (Fondell et al., 1993, 1996) led to the hypothesis of a correlation between the capacity of TR to interfere with transcription pre-initiation complex formation and its ability to bind TBP and TFIIB. As shown in Figure 7, while both TR and v-ErbA can bind to TBP, $\mathrm{v}$-ErbA is moderately impaired in direct binding to TFIIB in an in vitro (Figure $6 \mathrm{~B}$ ) and an in vivo assay (Figure $7 \mathrm{C}$ ). It is possible that v-ErbA is deficient in an interaction with an additional component of the transcriptional apparatus or some regulatory macromolecular complex known to interact with NHRs (Lee et al., 1995; Rachez et al., 1998). Biochemical analysis revealed the unexpected capacity of $\mathrm{v}$-ErbA to associate with several currently unidentified polypeptides in the oocyte that do not bind to unliganded TR (F.D.Urnov, unpublished observations). It is possible that such interactions represent mutation-induced de novo acquisitions relative to TR and obstruct surfaces on the LBD of v-ErbA that are used by TR to effect repression; future studies will exploit the biochemical approach described here to study such differences between v-ErbA and unliganded gag-tagged TR in repression-related protein-protein interactions.

In a previous study with an in vitro system, excess TBP was used to saturate repression-related interaction interfaces on the surface of TR and abrogate transcriptional repression (Fondell et al., 1996). In the oocyte, however, overexpression of TBP failed to relieve TR-driven repression on both TATA-less (TR $\beta A$ ) and TATAcontaining (HSV-tk) promoters (F.D.Urnov, unpublished observations); this was surprising, considering that the oocyte contains very little endogenous TBP (Veenstra et al., 1999), and that a highly sensitive luciferase assay was used that could detect even marginal effects. Thus, solid evidence regarding the existence and relevance of a basal machinery-directed repression pathway by TR in vivo remains to be obtained for any system, and other pathways for repression, e.g. the relocalization of TR-bound DNA to a transcriptionally incompetent nuclear domain (Dernburg et al., 1996), deserve investigation.

Whatever the precise molecular underpinnings of nonHDAC-based repression pathways in TR function, it is useful to consider that unliganded TR maintains many cell types in metazoa in the proliferative state (Brown et al., 1995; Beug et al., 1996), where loci repressed by TR undergo repeated cycles of chromatin disassembly and reassembly (Adams and Kamakaka, 1999). On immature chromatin templates, pathways for repression auxiliary to HDAC targeting may provide a useful means for the maintenance of transcriptional silencing, while the N-CoR-HDAC3 pathway described here may accelerate the maturation of chromatin in a locus-specific fashion.

\section{Materials and methods}

\footnotetext{
Plasmid constructs for transcription analysis and in vitro mRNA synthesis

Transcription assays were performed using pTRßA (Wong et al., 1995) as a reporter construct; this plasmid contains a fragment of the Xenopus laevis TRßA gene (Shi et al., 1992) corresponding to positions (-1335)$(+313)$ relative to the major transcription start site (Wong et al., 1998a) fused to a $275 \mathrm{bp}$ fragment of the CAT gene and cloned into pBluescript II $\mathrm{KS}(-)$ (Stratagene, La Jolla, CA). The coding portions of the various v-ErbA alleles of Gallus gallus TR $\alpha$ (NR1A1; Committee, 1999) and of the gag-TR $\alpha$ fusion (Zenke et al., 1990) were obtained from cognate
} 
clones in pSFCV-LE (Fuerstenberg et al., 1990) by PCR and cloned into pT7-TS (Zorn and Krieg, 1997) between an X.laevis $\beta$-globin $5^{\prime}$ and $3^{\prime}$ untranslated region. The clone for X.laevis TR $\beta$ (NR1A2) in pSP64(A) (Promega, Madison, WI) was a kind gift from Dr D.Brown (Carnegie Institute); the clone of X.laevis RXR $\alpha$ (NR2B1) was described previously (Wong et al., 1995). All plasmids were linearized with EcoRI and used as templates in capped mRNA synthesis reactions using mMessage mMachine in vitro transcription kits (Ambion, Austin, TX) driven by SP6 (Xenopus TR $\beta$ and RXR $\alpha$ ) or T7 (all other constructs) polymerase.

\section{Preparation, microinjection and maintenance of oocytes}

Stage VI X.laevis oocytes were prepared as described previously (Almouzni and Wolffe, 1993a). For each experimental sample, 25-30 healthy oocytes were injected into the cytoplasm with $0.25-10 \mathrm{ng}$ of mRNA (see specific figure legends for amount) in 32.2-41.4 nl of diethyl pyrocarbonate (DEPC)-treated water and cultured in modified Barth's solution (MBSH) buffer (Gurdon, 1968) for $8-12 \mathrm{~h}$ at $18^{\circ} \mathrm{C}$; where indicated, $10 \mu \mathrm{Ci} / \mathrm{ml}$ of in vivo cell labeling grade $\left.\mathrm{L}-{ }^{35} \mathrm{~S}\right]$ methionine (Amersham Pharmacia Biotech, Arlington Heights, IL) were added to the medium. Following translation of the injected mRNA, 0.5-1.0 ng of pTR $\beta A$ DNA purified from E.coli by gravity flow on anion-exchange resin (Qiagen, Valencia, CA) was injected into the nucleus in $13.8 \mathrm{nl}$ of DEPC-treated water, and the oocytes were cultured as above for 14-16 h, or for the length of time stated in the figure legends. Where indicated, $100 \mathrm{nM}$ 3,3',5-triiodo-L-thyronine (Sigma Chemical, St Louis, MO) or 33 nM TSA (Wako Chemicals, Richmond, VA) was included in the culture medium.

\section{Protein isolation}

Following mRNA microinjection and subsequent culture (see above), 10 healthy oocytes were homogenized in $50-100 \mu \mathrm{l}$ of $20 \mathrm{mM}$ Tris-Cl $\mathrm{pH} 7.5,50 \mathrm{mM} \mathrm{KCl}, 1 \mathrm{mM}$ dithiothreitol (DTT), $0.5 \mathrm{mM}$ phenylmethylsulfonyl fluoride (PMSF), 8\% glycerol. Debris and yolk were pelleted in a microcentrifuge for $15 \mathrm{~min}$ at $4^{\circ} \mathrm{C}$, and the cleared supernatant was stored at $-70^{\circ} \mathrm{C}$ until use. In vitro translated proteins were synthesized in rabbit reticulocyte lysate by using $1 \mu \mathrm{g}$ of supercoiled plasmid DNA template in a TnT Coupled (Xenopus RXR $\alpha$ ) or Quick Coupled (all other proteins) transcription/translation reaction (Promega). For in vivo labeling analysis, extract from 1 oocyte equivalent per experimental sample was fractionated on a $4 \%$ stacking/10\% resolving SDS-PAGE (Laemmli, 1970); the gel was dried and autoradiographed.

\section{RNA isolation and transcript analysis by primer extension}

Total RNA was extracted from 18-20 oocytes per experimental sample as previously described (Wong et al., 1995), with modifications: the oocytes were rinsed with MBSH buffer, homogenized in $200 \mu \mathrm{l}$ of $0.25 \mathrm{M}$ Tris-Cl $\mathrm{pH} 7.5$, and mixed with $500 \mu \mathrm{l}$ of RNAzol B (TelTest, Friendswood, TX). After addition of $50 \mu \mathrm{l}$ of chloroform, a 15 min incubation on ice and microcentrifugation for $15 \mathrm{~min}$, the aqueous phase was removed and RNA precipitated by addition of an equal volume of isopropanol, incubation on ice for $15 \mathrm{~min}$, and microcentrifugation. The pellet was rinsed with 70\% ethanol, resuspended in TE buffer $\mathrm{pH} 7.5$, and the RNA was precipitated with $\mathrm{LiCl}$. The pellet was rinsed with $70 \%$ ethanol and resuspended in DEPC-treated water to one oocyte equivalent $/ \mu 1$. Three to five oocyte equivalents of RNA were annealed in $0.6 \times$ First Strand reverse transcriptase buffer ( $30 \mathrm{mM}$ Tris- $\mathrm{Cl} \mathrm{pH} 8.3,45 \mathrm{mM} \mathrm{KCl}, 1.8 \mathrm{mM}$ $\mathrm{MgCl}_{2}, 3 \mathrm{mM}$ DTT final; Life Technologies, Gaithersburg, MD) to 0.2 pmol each of end-labeled primer H4 (Wong et al., 1998b) and endlabeled primer I (Wong et al., 1995); the former anneals to histone $\mathrm{H} 4$ mRNA stored in the oocyte, whereas the latter anneals at positions (+80)$(+109)$ to the mRNA transcribed from the TR $\beta A$ gene. The annealing regimen was as follows: $10 \mathrm{~min}$ at $65^{\circ} \mathrm{C}, 30 \mathrm{~min}$ at $55^{\circ} \mathrm{C}, 20 \mathrm{~min}$ at $37^{\circ} \mathrm{C}$ and $5 \mathrm{~min}$ at room temperature. The primer extension was performed with $100 \mathrm{U}$ of SuperScript II RNase $\mathrm{H}^{-}$reverse transcriptase, $2 \mathrm{U}$ of RNase inhibitor (both from Life Technologies), and $75 \mu \mathrm{M}$ each dNTP for $1 \mathrm{~h}$ at $42^{\circ} \mathrm{C}$. Reaction products were precipitated with ethanol, resolved on a $6 \%$ urea-PAGE in $1 \times \mathrm{TBE}$, and analyzed by exposure to Molecular Dynamics PhosphorImager screens or Kodak X-OMAT/AR X-ray film at room temperature.

\section{Analysis of chromatin assembly in vivo}

A large group of oocytes was injected with 3 ng of TR $\beta A$ DNA. For topological analysis, at defined timepoints following injection, 10 healthy

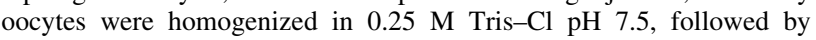
addition of an equal volume of stop buffer (30 mM EDTA pH 8.0,20 mM Tris- $\mathrm{Cl} \mathrm{pH} 7.5,1 \% \mathrm{SDS}$ ), and DNA purification via proteinase $\mathrm{K}$ treatment and phenol extraction as described above for DNase I analysis.
DNA from 0.5 oocyte equivalents was fractionated on a $1 \%$ agarose gel in $1 \times$ TPE buffer containing $90 \mu \mathrm{g} / \mathrm{ml}$ chloroquine as described (Clark and Wolffe, 1991; Clark, 1998). For nucleosome density measurements, 30 healthy oocytes removed at each timepoint were homogenized in $300 \mu \mathrm{l}$ of buffer C (15 mM Tris pH 7.5, $60 \mathrm{mM} \mathrm{KCl}, 15 \mathrm{mM} \mathrm{NaCl}, 10 \mathrm{mM}$ $\mathrm{NaHSO}_{3}, 0.34 \mathrm{M}$ sucrose, $0.15 \mathrm{mM} \beta$-mercaptoethanol; Kornberg et al., 1989); the homogenate was split into three aliquots of $100 \mu$ l, to one of which an equal volume of stop buffer was immediately added and DNA extracted as above. To the remaining two aliquots, $\mathrm{CaCl}_{2}$ was added to a final concentration of $3 \mathrm{mM}$, the samples were immediately warmed to $37^{\circ} \mathrm{C}$ for $1 \mathrm{~min}$, and treated with 30 or 120 Worthington units of MNase (NFCP grade, Worthington) for $2 \mathrm{~min}$ at $37^{\circ} \mathrm{C}$. The reactions were stopped and the DNA extracted as described above. One oocyte equivalent from each sample was fractionated on a $2 \%$ high-resolution blend agarose (Amresco) gel in $1 \times$ Tris-acetate-EDTA. Southern blotting with random-primed probes was performed as described above.

\section{Immunoprecipitations from whole oocyte and egg extract} Oocytes were injected with the indicated amounts of mRNA and cultured for $12-24 \mathrm{~h}$ at $18^{\circ} \mathrm{C}$ in $\mathrm{MBSH}$ medium containing $\left.{ }^{35} \mathrm{~S}\right]$ methionine. The oocytes were rinsed with MBSH and homogenized in 5-10 $\mu 1 /$ oocyte of extraction buffer (Jones et al., 1998): $20 \mathrm{mM}$ HEPES pH 7.5, $5 \mathrm{mM} \mathrm{KCl}$, $1.5 \mathrm{mM} \mathrm{MgCl}_{2}, 1 \mathrm{mM}$ EGTA, $10 \mathrm{mM} \beta$-glycerophosphate, $0.05 \% \mathrm{NP}-40$, $0.5 \mathrm{mM}$ DTT, $0.2 \mathrm{mM}$ PMSF, $1 \mu \mathrm{g} / \mathrm{ml}$ leupeptin, $2 \mu \mathrm{g} / \mathrm{ml}$ pepstatin, $3 \mu \mathrm{g} /$ $\mathrm{ml}$ aprotinin. $\mathrm{NaCl}$ was added to the buffer to $5-95 \mathrm{mM}$ where indicated. All subsequent manipulations were performed in the cold room. The homogenate was centrifuged at 14000 r.p.m. in a benchtop mictrocentrifuge and the clear middle layer was removed for experimentation. Ascites fluid containing mouse monoclonal antibody against the AEV gag protein (Bauer et al., 1998) was used at a dilution of 1:500; the oocyte extract was mixed with the antibody for $30 \mathrm{~min}$ prior to addition of $5 \mu \mathrm{l}$ bed volume of protein G-Sepharose beads (Amersham Pharmacia Biotech) that were blocked by rotating in extraction buffer containing $200 \mu \mathrm{g} / \mathrm{ml}$ bovine serum albumin (BSA) for $1 \mathrm{~h}$. The protein extract and the beads were mixed by rotation for 2-6h, pelleted for $15 \mathrm{~s}$ at $3000 \mathrm{r.p.m}$. and washed three times with $400 \mu$ of extraction buffer containing, where indicated, additional $\mathrm{NaCl}$ and NP-40 (see figure legends). For analysis of gag-TR association, a small volume of concentrated $\mathrm{T}_{3}$ in $100 \mathrm{mM} \mathrm{NaOH}$ was added to a final concentration of $1-2.5 \mu \mathrm{M}$ to the homogenization/ binding and wash solutions, and an identical volume of $100 \mathrm{mM} \mathrm{NaOH}$ was added to these solutions for other samples. The beads were resuspended into extraction buffer and aliquoted for analysis.

For experiments with egg extract prepared as described (Wade et al., $1999 b), 5-10 \mu$ l of glutathione-Sepharose (Amersham Pharmacia) matrix with immobilized GST or GST-TR (residues 169-456 of human TR $\beta$; Tone et al., 1994) or CnBr-activated Sepharose (Amersham Pharmacia) with serum crosslinked and treated with dimethylpimelimidate as described (Harlow and Lane, 1999) were blocked with $0.2-0.5 \mathrm{mg} / \mathrm{ml}$ BSA and added to $200-400 \mu \mathrm{l}$ of egg extract adjusted with $\mathrm{NaCl}$ and NP-40 to the concentration indicated. Following binding in the cold room, the matrix was washed three times with $400 \mu 1$ of immunoprecipitation buffer, and the bound protein was eluted by boiling in SDS-PAGE sample buffer or by $0.2 \mathrm{M}$ glycine $\mathrm{pH} 2.5$.

\section{Western blotting}

Bead and input samples were boiled in SDS-PAGE loading buffer, fractionated on conventional 6 or 10\% Laemmli SDS-PAGE or on 4-12 or 4-20\% PAGE (Novex), and then transferred to Hybond ECL nitrocellulose membranes (Amersham Pharmacia Biotech). The membranes were blocked for $1 \mathrm{~h}$ at room temperature or overnight at $4^{\circ} \mathrm{C}$ in a

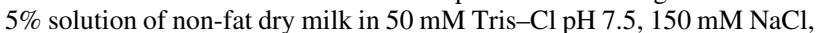
$0.05 \%$ Tween 20 (Sigma, St. Louis, MO) and probed with the following antibodies, listed as 'protein, species of target antigen, dilution, reference': N-CoR, Xenopus, 1:500 (P.Jones, L.Sachs and Y.-B.Shi, manuscript submitted); Sin3A/B, Xenopus, 1:1000 (Jones et al., 1998); HDAC1/RPD3, Xenopus, 1:2500 (Vermaak et al., 1999); Mi-2, Xenopus, 1:1000 (Wade et al., 1999a); HDAC5, Mus musculus, 1:1000 (generous gift of Saadi Khochbin); HDAC3, Homo sapiens, 1:500 or 1:250 (Upstate Biotechnology, Lake Placid, NY); TFIIB, H.sapiens, 1:500 (C18; Santa Cruz Biotechnology). Detection with secondary antibody conjugated to HRP (Amersham Pharmacia Biotech) and ECL reagents (Pierce) was performed according to the manufacturers' instructions.

\section{GST pulldown assay}

Human TBP (Ge and Roeder, 1994) and human TFIIB fused to GST (gift of $\mathrm{Dr}$ Hui Ge) were expressed in E.coli and purified by affinity chromatography on glutathione-Sepharose 4B (Amersham Pharmacia 
Biotech) as recommended by the manufacturer; the fusion protein was not eluted from the matrix. Chicken TR $\alpha$ and v-ErbA were synthesized in vitro using rabbit reticulocyte lysate (TnT Quick Coupled System; Promega) and evaluated for their ability to bind either protein in a GST pulldown assay as described (Tone et al., 1994), with modifications: non-specific binding sites on the matrix were saturated by rotation in the presence of $0.5 \mathrm{mg} / \mathrm{ml} \mathrm{BSA}$ for $30 \mathrm{~min}$ at room temperature in pulldown buffer (Tone et al., 1994), and, following incubation with the in vitro synthesized protein, the matrix was washed twice with $250 \mu \mathrm{l}$ of phosphate-buffered saline (PBS) containing an additional $350 \mathrm{mM} \mathrm{NaCl}$ and $0.1 \% \mathrm{NP}-40 . \mathrm{T}_{3}$ was added in $1 \mathrm{mM} \mathrm{NaOH}$ to a final concentration of $1 \mu \mathrm{M}$ where indicated, and an equal volume of $1 \mathrm{mM} \mathrm{NaOH}$ was added to the other samples.

\section{Acknowledgements}

We thank Saadi Khochbin for the antibody against HDAC5, Hui Ge for the TBP and TFIIB fusion constructs, and Paul Wade for egg extract and hyperacetylated tritiated histones. F.D.U. expresses his sincere gratitude to Paul Wade, Peter Jones, GertJan Veenstra and Yoshiaki Azuma for their invaluable advice and stimulating discussions throughout the course of this work.

\section{References}

Adams,C.R. and Kamakaka,R.T. (1999) Chromatin assembly: biochemical identities and genetic redundancy. Curr. Opin. Genet. Dev., 9, 185-190.

Almouzni,G. and Wolffe,A.P. (1993a) Nuclear assembly, structure, and function: the use of Xenopus in vitro systems. Exp. Cell Res., 205, 115.

Almouzni,G. and Wolffe,A.P. (1993b) Replication-coupled chromatin assembly is required for the repression of basal transcription in vivo. Genes Dev., 7, 2033-2047.

Almouzni,G., Mechali,M. and Wolffe,A.P. (1990) Competition between transcription complex assembly and chromatin assembly on replicating DNA. EMBO J., 9, 573-582.

Baniahmad,A., Ha,I., Reinberg,D., Tsai,S., Tsai,M.J. and O'Malley,B.W. (1993) Interaction of human thyroid hormone receptor $\beta$ with transcription factor TFIIB may mediate target gene derepression and activation by thyroid hormone. Proc. Natl Acad. Sci. USA, 90, 88328836.

Bauer,A., Mikulits,W., Lagger,G., Stengl,G., Brosch,G. and Beug,H. (1998) The thyroid hormone receptor functions as a ligand-operated developmental switch between proliferation and differentiation of erythroid progenitors. EMBO J., 17, 4291-4303.

Beug,H., Mullner,E.W. and Hayman,M.J. (1994) Insights into erythroid differentiation obtained from studies on avian erythroblastosis virus. Curr. Opin. Cell Biol., 6, 816-824.

Beug,H., Bauer,A., Dolznig,H., von Lindern,M., Lobmayer,L., Mellitzer,G., Steinlein,P., Wessely,O. and Mullner,E. (1996) Avian erythropoiesis and erythroleukemia: towards understanding the role of the biomolecules involved. Biochim. Biophys. Acta, 1288, M35-M47.

Brehm,A., Miska,E.A., McCance,D.J., Reid,J.L., Bannister,A.J. and Kouzarides,T. (1998) Retinoblastoma protein recruits histone deacetylase to repress transcription. Nature, 391, 597-601.

Brown,D.D., Wang,Z., Kanamori,A., Eliceiri,B., Furlow,J.D. and Schwartzman,R. (1995) Amphibian metamorphosis: a complex program of gene expression changes controlled by the thyroid hormone. Recent Prog. Horm. Res., 50, 309-315.

Chen,G., Fernandez,J., Mische,S. and Courey,A.J. (1999) A functional interaction between the histone deacetylase rpd3 and the corepressor groucho in Drosophila development. Genes Dev., 13, 2218-2230.

Chen,J.D. and Evans,R.M. (1995) A transcriptional co-repressor that interacts with nuclear hormone receptors. Nature, 377, 454-457.

Clark,D.J. (1998) Counting nucleosome cores on circular DNA using topoisomerase I. In Gould,H. (ed.), Chromatin. IRL Practical Approach Series. Oxford University Press, Oxford, UK, pp. 139-152.

Clark,D.J. and Wolffe,A.P. (1991) Superhelical stress and nucleosomemediated repression of 5S RNA gene transcription in vitro. EMBO J., 10, 3419-3428.

Committee (1999) A unified nomenclature system for the nuclear receptor superfamily. Cell, 97, 161-163.

Damm,K., Thompson,C.C. and Evans,R.M. (1989) Protein encoded by
v-erbA functions as a thyroid-hormone receptor antagonist. Nature, 339, 593-597.

Dangond,F., Hafler,D.A., Tong,J.K., Randall,J., Kojima,R., Utku,N. and Gullans,S.R. (1998) Differential display cloning of a novel human histone deacetylase (HDAC3) cDNA from PHA-activated immune cells. Biochem. Biophys. Res. Commun., 242, 648-652.

Danielian,P.S., White,R., Lees,J.A. and Parker,M.G. (1992) Identification of a conserved region required for hormone dependent transcriptional activation by steroid hormone receptors. EMBO J., 11, $1025-1033$.

Dernburg,A.F., Broman,K.W., Fung,J.C., Marshall,W.F., Philips,J., Agard,D.A. and Sedat,J.W. (1996) Perturbation of nuclear architecture by long-distance chromosome interactions. Cell, $\mathbf{8 5}$, $745-759$.

Dressel,U., Thormeyer,D., Altincicek,B., Paululat,A., Eggert,M., Schneider,S., Tenbaum,S.P., Renkawitz,R. and Baniahmad,A. (1999) Alien, a highly conserved protein with characteristics of a corepressor for members of the nuclear hormone receptor superfamily. Mol. Cell. Biol., 19, 3383-3394.

Emiliani,S., Fischle,W., Van Lint,C., Al-Abed,Y. and Verdin,E. (1998) Characterization of a human RPD3 ortholog, HDAC3. Proc. Natl Acad. Sci. USA, 95, 2795-2800.

Fondell,J.D., Roy,A.L. and Roeder,R.G. (1993) Unliganded thyroid hormone receptor inhibits formation of a functional preinitiation complex: implications for active repression. Genes Dev., 7, 14001410.

Fondell,J.D., Brunel,F., Hisatake,K. and Roeder,R.G. (1996) Unliganded thyroid hormone receptor $\alpha$ can target TATA-binding protein for transcriptional repression. Mol. Cell. Biol., 16, 281-287.

Fuerstenberg,S. et al. (1990) Ectopic expression of the erythrocyte band 3 anion exchange protein, using a new avian retrovirus vector. J. Virol., 64, 5891-5902.

Ge,H. and Roeder,R.G. (1994) The high mobility group protein HMG1 can reversibly inhibit class II gene transcription by interaction with the TATA-binding protein. J. Biol. Chem., 269, 17136-17140.

Guenther,M.G., Lane,W.S., Fischle,W., Verdin,E., Lazar,M.A. and Shiekhattar,R. (2000) A core SMRT corepressor complex containing HDAC3 and TBL1, a WD40-repeat protein linked to deafness. Genes Dev., 14, 1048-1057.

Gurdon,J.B. (1968) Changes in somatic cell nuclei inserted into growing and maturing amphibian oocytes. J. Embryol. Exp. Morphol., 20, 401414.

Hanna-Rose,W. and Hansen,U. (1996) Active repression mechanisms of eukaryotic transcription repressors. Trends Genet., 12, 229-234.

Harlow,E. and Lane,D. (1999) Using Antibodies: A Laboratory Manual. Cold Spring Harbor Laboratory Press, Cold Spring Harbor, NY.

Hassig,C.A., Fleischer,T.C., Billin,A.N., Schreiber,S.L. and Ayer,D.E. (1997) Histone deacetylase activity is required for full transcriptional repression by $\mathrm{mSin} 3 \mathrm{~A}$. Cell, $\mathbf{8 9}, 341-347$.

Haussler,M.R., Haussler,C.A., Jurutka,P.W., Thompson,P.D., Hsieh,J.C., Remus,L.S., Selznick,S.H. and Whitfield,G.K. (1997) The vitamin D hormone and its nuclear receptor: molecular actions and disease states. J. Endocrinol., 154, S57-S73.

Heinzel,T. et al. (1997) A complex containing N-CoR, mSin3 and histone deacetylase mediates transcriptional repression. Nature, 387, 43-48.

Hoerlein,A.J. et al. (1995) Ligand-independent repression by the thyroid hormone receptor mediated by a nuclear receptor co-repressor. Nature, 377, 397-404.

Huang,E.Y., Zhang,J., Miska,E.A., Guenther,M.G., Kouzarides,T. and Lazar,M.A. (2000) Nuclear receptor corepressors partner with class II histone deacetylases in a Sin3-independent repression pathway. Genes Dev., 14, 45-54.

Jones,P.L., Veenstra,G.J., Wade,P.A., Vermaak,D., Kass,S.U., Landsberger,N., Strouboulis,J. and Wolffe,A.P. (1998) Methylated DNA and MeCP2 recruit histone deacetylase to repress transcription. Nature Genet., 19, 187-191.

Kao,H.Y., Downes,M., Ordentlich,P. and Evans,R.M. (2000) Isolation of a novel histone deacetylase reveals that class I and class II deacetylases promote SMRT-mediated repression. Genes Dev., 14, $55-66$.

Kass,S.U., Landsberger,N. and Wolffe,A.P. (1997) DNA methylation directs a time-dependent repression of transcription initiation. Curr. Biol., 7, 157-165.

Koipally,J., Renold,A., Kim,J. and Georgopoulos,K. (1999) Repression by Ikaros and Aiolos is mediated through histone deacetylase complexes. EMBO J., 18, 3090-3100. 
Kornberg,R.D., LaPointe,J.W. and Lorch,Y. (1989) Preparation of nucleosomes and chromatin. Methods Enzymol., 170, 3-14.

Laemmli,U.K. (1970) Cleavage of structural proteins during the assembly of the head of bacteriophage T4. Nature, 227, 680-685.

Laherty,C.D., Yang,W.M., Sun,J.M., Davie,J.R., Seto,E. and Eisenman,R.N. (1997) Histone deacetylases associated with the mSin3 corepressor mediate mad transcriptional repression. Cell, 89, 349-356.

Lai,A., Lee,J.M., Yang,W.-M., DeCaprio,J.A., Kaelin,W.G., Seto,E. and Branton,P.E. (1999) RBP1 recruits both histone deacetylasedependent and -independent repression activities to retinoblastoma family proteins. Mol. Cell. Biol., 19, 6632-6641.

Lavigne,A.C., Mengus,G., Gangloff,Y.G., Wurtz,J.M. and Davidson,I. (1999) Human $\mathrm{TAF}_{\mathrm{II}} 55$ interacts with the vitamin $\mathrm{D}_{3}$ and thyroid hormone receptors and with derivatives of the retinoid $\mathrm{X}$ receptor that have altered transactivation properties. Mol. Cell. Biol., 19, 54865494.

Lee,J.W., Choi,H.S., Gyuris,J., Brent,R. and Moore,D.D. (1995) Two classes of proteins dependent on either the presence or absence of thyroid hormone for interaction with the thyroid hormone receptor. Mol. Endocrinol., 9, 243-254.

Luo,R.X., Postigo,A.A. and Dean,D.C. (1998) Rb interacts with histone deacetylase to repress transcription. Cell, 92, 463-473.

Machuca,I., Esslemont,G., Fairclough,L. and Tata,J.R. (1995) Analysis of structure and expression of the Xenopus thyroid hormone receptor $\beta$ gene to explain its autoinduction. Mol. Endocrinol., 9, 96-107.

Magnaghi-Jaulin,L., Groisman,R., Naguibneva,I., Robin,P., Lorain,S., Le Villain,J.P., Troalen,F., Trouche,D. and Harel-Bellan,A. (1998) Retinoblastoma protein represses transcription by recruiting a histone deacetylase. Nature, 391, 601-605.

Mannervik,M. and Levine,M. (1999) The Rpd3 histone deacetylase is required for segmentation of the Drosophila embryo. Proc. Natl Acad. Sci. USA, 96, 6797-6801.

Moras,D. and Gronemeyer,H. (1998) The nuclear receptor ligandbinding domain: structure and function. Curr. Opin. Cell Biol., 10, 384-391.

Munoz,A., Zenke,M., Gehring,U., Sap,J., Beug,H. and Vennstrom,B. (1988) Characterization of the hormone-binding domain of the chicken c-erbA/thyroid hormone receptor protein. EMBO J., 7, 155159.

Muscat,G.E., Burke,L.J. and Downes,M. (1998) The corepressor N-CoR and its variants RIP13a and RIP13 1 directly interact with the basal transcription factors TFIIB, TAFII32 and TAFII70. Nucleic Acids Res., 26, 2899-2907.

Nagy,L., Kao,H.Y., Chakravarti,D., Lin,R.J., Hassig,C.A., Ayer,D.E., Schreiber,S.L. and Evans,R.M. (1997) Nuclear receptor repression mediated by a complex containing SMRT, mSin3A, and histone deacetylase. Cell, 89, 373-380.

Nan,X., Ng,H.H., Johnson,C.A., Laherty,C.D., Turner,B.M., Eisenman,R.N. and Bird,A. (1998) Transcriptional repression by the methyl-CpG-binding protein MeCP2 involves a histone deacetylase complex. Nature, 393, 386-389.

Rachez,C., Suldan,Z., Ward,J., Chang,C.P., Burakov,D., ErdjumentBromage,H., Tempst,P. and Freedman,L.P. (1998) A novel protein complex that interacts with the vitamin D3 receptor in a liganddependent manner and enhances VDR transactivation in a cell-free system. Genes Dev., 12, 1787-1800.

Rundlett,S.E., Carmen,A.A., Kobayashi,R., Bavykin,S., Turner,B.M. and Grunstein,M. (1996) HDA1 and RPD3 are members of distinct yeast histone deacetylase complexes that regulate silencing and transcription. Proc. Natl Acad. Sci. USA, 93, 14503-14508.

Saatcioglu,F., Bartunek,P., Deng,T., Zenke,M. and Karin,M. (1993) A conserved C-terminal sequence that is deleted in v-ErbA is essential for the biological activities of c-ErbA (the thyroid hormone receptor). Mol. Cell. Biol., 13, 3675-3685.

Samuels,H.H., Perlman,A.J., Raaka,B.M. and Stanley,F. (1982) Organization of the thyroid hormone receptor in chromatin. Recent Prog. Horm. Res., 38, 557-599.

Sap,J., Munoz,A., Damm,K., Goldberg,Y., Ghysdael,J., Leutz,A., Beug,H. and Vennstrom,B. (1986) The c-erb-A protein is a highaffinity receptor for thyroid hormone. Nature, 324, 635-640.

Sap,J., Munoz,A., Schmitt,J., Stunnenberg,H. and Vennstrom,B. (1989) Repression of transcription mediated at a thyroid hormone response element by the v-erb-A oncogene product. Nature, 340, 242-244.

Seol,W., Choi,H.S. and Moore,D.D. (1995) Isolation of proteins that interact specifically with the retinoid $\mathrm{X}$ receptor: two novel orphan receptors. Mol. Endocrinol., 9, 72-85.
Shi,Y.B., Yaoita,Y. and Brown,D.D. (1992) Genomic organization and alternative promoter usage of the two thyroid hormone receptor $\beta$ genes in Xenopus laevis. J. Biol. Chem., 267, 733-738.

Shimamura,A. and Worcel,A. (1989) The assembly of regularly spaced nucleosomes in the Xenopus oocyte S-150 extract is accompanied by deacetylation of histone H4. J. Biol. Chem., 264, 14524-14530.

Stunnenberg,H.G., Garcia-Jimenez,C. and Betz,J.L. (1999) Leukemia: the sophisticated subversion of hematopoiesis by nuclear receptor oncoproteins. Biochim. Biophys. Acta, 1423, F15-F33.

Sucov,H.M. and Evans,R.M. (1995) Retinoic acid and retinoic acid receptors in development. Mol. Neurobiol., 10, 169-184.

Tata,J.R. (1996) Metamorphosis: an exquisite model for hormonal regulation of post-embryonic development. Biochem. Soc. Symp., 62, 123-136.

Tone,Y., Collingwood,T.N., Adams,M. and Chatterjee,V.K. (1994) Functional analysis of a transactivation domain in the thyroid hormone $\beta$ receptor. J. Biol. Chem., 269, 31157-31161.

Tong,G.X., Tanen,M.R. and Bagchi,M.K. (1995) Ligand modulates the interaction of thyroid hormone receptor $\beta$ with the basal transcription machinery. J. Biol. Chem., 270, 10601-10611.

Torchia,J., Glass,C. and Rosenfeld,M.G. (1998) Co-activators and corepressors in the integration of transcriptional responses. Curr. Opin. Cell Biol., 10, 373-383.

Ura,K., Kurumizaka,H., Dimitrov,S., Almouzni,G. and Wolffe,A.P. (1997) Histone acetylation: influence on transcription, nucleosome mobility and positioning, and linker histone-dependent transcriptional repression. EMBO J., 16, 2096-2107.

Veenstra,G.J., Destree,O.H. and Wolffe,A.P. (1999) Translation of maternal TATA-binding protein mRNA potentiates basal but not activated transcription in Xenopus embryos at the midblastula transition. Mol. Cell. Biol., 19, 7972-7982.

Vermaak,D., Wade,P.A., Jones,P.L., Shi,Y.B. and Wolffe,A.P. (1999) Functional analysis of the SIN3-histone deacetylase RPD3-RbAp48histone $\mathrm{H} 4$ connection in the Xenopus oocyte. Mol. Cell. Biol., 19, $5847-5860$.

Wade,P.A., Jones,P.L., Vermaak,D. and Wolffe,A.P. (1998) A multiple subunit Mi-2 histone deacetylase from Xenopus laevis cofractionates with an associated Snf2 superfamily ATPase. Curr. Biol., 8, 843-846.

Wade,P.A., Gegonne,A., Jones,P.L., Ballestar,E., Aubry,F. and Wolffe,A.P. (1999a) Mi-2 complex couples DNA methylation to chromatin remodelling and histone deacetylation. Nature Genet., 23, 62-66.

Wade,P.A., Jones,P.L., Vermaak,D. and Wolffe,A.P. (1999b) Purification of a histone deacetylase complex from Xenopus laevis: preparation of substrates and assay procedures. Methods Enzymol., 304, 715-725.

Weinberger,C., Thompson,C.C., Ong,E.S., Lebo,R., Gruol,D.J. and Evans,R.M. (1986) The c-erb-A gene encodes a thyroid hormone receptor. Nature, 324, 641-646.

Wolffe,A.P. (1997) Transcriptional control. Sinful repression. Nature, 387, 16-17.

Wong,C.W. and Privalsky,M.L. (1998) Transcriptional repression by the SMRT-mSin3 corepressor: multiple interactions, multiple mechanisms, and a potential role for TFIIB. Mol. Cell. Biol., 18, $5500-5510$.

Wong,J., Shi,Y.B. and Wolffe,A.P. (1995) A role for nucleosome assembly in both silencing and activation of the Xenopus TR $\beta$ A gene by the thyroid hormone receptor. Genes Dev., 9, 2696-2711.

Wong,J., Shi,Y.B. and Wolffe,A.P. (1997) Determinants of chromatin disruption and transcriptional regulation instigated by the thyroid hormone receptor: hormone-regulated chromatin disruption is not sufficient for transcriptional activation. EMBO J., 16, 3158-3171.

Wong,J., Liang,V.C., Sachs,L.M. and Shi,Y.B. (1998a) Transcription from the thyroid hormone-dependent promoter of the Xenopus laevis thyroid hormone receptor $\beta \mathrm{A}$ gene requires a novel upstream element and the initiator, but not a TATA box. J. Biol. Chem., 273, 1418614193.

Wong,J., Patterton,D., Imhof,A., Guschin,D., Shi,Y.B. and Wolffe,A.P. (1998b) Distinct requirements for chromatin assembly in transcriptional repression by thyroid hormone receptor and histone deacetylase. EMBO J., 17, 520-534.

Xu,L., Glass,C.K. and Rosenfeld,M.G. (1999) Coactivator and corepressor complexes in nuclear receptor function. Curr. Opin. Genet. Dev., 9, 140-147.

Xue,Y., Wong,J., Moreno,G.T., Young,M.K., Cote,J. and Wang,W. (1998) NURD, a novel complex with both ATP-dependent chromatinremodeling and histone deacetylase activities. Mol. Cell, 2, 851-861. 
Yang,W.M., Yao,Y.L., Sun,J.M., Davie,J.R. and Seto,E. (1997) Isolation and characterization of cDNAs corresponding to an additional member of the human histone deacetylase gene family. J. Biol. Chem., 272, 28001-28007.

Zenke,M., Munoz,A., Sap,J., Vennstrom,B. and Beug,H. (1990) v-erbA oncogene activation entails the loss of hormone-dependent regulator activity of c-erbA. Cell, 61, 1035-1049.

Zhang,Y., Iratni,R., Erdjument-Bromage,H., Tempst,P. and Reinberg,D. (1997) Histone deacetylases and SAP18, a novel polypeptide, are components of a human Sin3 complex. Cell, 89, 357-364.

Zorn,A.M. and Krieg,P.A. (1997) The KH domain protein encoded by quaking functions as a dimer and is essential for notochord development in Xenopus embryos. Genes Dev., 11, 2176-2190.

Received February 24, 2000; revised June 1, 2000;

accepted June 16, 2000

\section{Note added in proof}

After the present work was submitted for publication, Guenther $e t$ al. (2000) reported the biochemical charcterization of a complex between the corepressor SMRT, HDAC3 and several additional polypeptides. In further agreement with our observations, this complex is reported not to contain HDAC1/RPD3 or Sin3. 